\title{
Flora da Bahia: Guapira (Nyctaginaceae)
}

\author{
Francisco Silva de Souza ${ }^{*}$, Jomar Gomes Jardim ${ }^{2, a}$ \& Alexa Araújo de Oliveira Paes Coelho ${ }^{3, b}$ \\ ${ }^{1}$ Programa de Pós-Graduação em Biodiversidade Vegetal, Universidade do Estado da Bahia, Brasil, Alagoinhas, \\ Bahia, Brasil. \\ ${ }^{2}$ Instituto de Humanidades, Artes e Ciências, Universidade Federal do Sul da Bahia, campus Jorge Amado, \\ Itabuna e Herbário Centro de Pesquisas do Cacau - CEPEC, Ilhéus, Bahia, Brasil. \\ ${ }^{3}$ Departamento de Ciências Exatas e da Terra, Universidade do Estado da Bahia, Alagoinhas, Bahia, Brasil.
}

Resumo - É apresentado o tratamento taxonômico de Guapira (Nyctaginaceae) do estado da Bahia, Brasil. Foram reconhecidas 12 espécies, incluindo G. noxia e G. tomentosa, ambas registradas pela primeira vez no estado. O tratamento inclui chave de identificação, descrições, comentários, além de ilustrações e mapas de distribuição geográfica das espécies na Bahia.

Palavras-chave adicionais: Caryophyllales, florística, Nordeste do Brasil, taxonomia.

\begin{abstract}
Flora of Bahia: Guapira (Nyctaginaceae)) - A taxonomic treatment of Guapira (Nyctaginaceae) from the state of Bahia, Brazil, is presented. Twelve species are recognized, including G. noxia and G. tomentosa, both reported for the first time in the state. The treatment includes an identification key, descriptions and comments, as well as illustrations and geographic distribution maps of the species in Bahia. Additional key words: Caryophyllales, floristic, Northeast Brazil, taxonomy.
\end{abstract}

\section{NyCTAGINACEAE}

Árvores, arbustos ou lianas. Folhas simples, alternas ou opostas, sem estípulas. Inflorescências geralmente cimosas, tirsiformes. Flores vistosas ou não, uni ou bissexuadas, glabras ou pilosas, monoclamídeas, brácteas evidentes ou não, geralmente actinomorfas; cálice (3-)5(-8)-mero, geralmente petaloide, gamossépalo, prefloração valvar; estames em número igual ao das sépalas, raramente em número menor ou maior, frequentemente conados, anteras rimosas; disco nectarífero frequente; ovário súpero, unicarpelar, uniovulado, placentação ereta. Frutos aquênios, envolvidos pela região basal do perianto, que é persistente, formando o antocarpo, indeiscente, coriáceo a carnoso, unisseminado; embrião curvo ou reto, periférico, endosperma rudimentar, perisperma abundante.

Nyctaginaceae está incluída na ordem Caryophyllales, possui cerca de 30 gêneros e 400 espécies, e está distribuída principalmente nas regiões tropicais e subtropicais do Novo Mundo, com três principais centros de diversidade: o primeiro na região do Caribe, o segundo nas zonas áridas da América do Norte ocidental (Douglas \& Spellenberg 2010) e o terceiro na América do Sul, com um elevado número de espécies na região da Bolívia, Peru e Brasil (Furlan \& Giulietti 2014). Para o Brasil, são referidos 11 gêneros e aproximadamente 50

\footnotetext{
*Autor para correspondência: frousa@gmail.com;

aj.jardim@yahoo.com.br; balexapaescoelho@gmail.com

Editor responsável: Alessandro Rapini

Submetido: 31 maio 2016; aceito: 1 nov. 2016

Publicação eletrônica: 17 nov. 2016; versão final: 21 nov. 2016
}

espécies, amplamente distribuídas em todas as Regiões do país, com maior representatividade em áreas de Mata Atlântica (Sá 2016).

\section{Guapira Aubl.}

Árvores, arbustos ou subarbustos; ramos estriados, lenticelados, glabros a pubescentes. Folhas opostas a subopostas, pecioladas a sésseis, glabras a pilosas; lâmina membranácea a coriácea, elíptica a cordiforme, base aguda, obtusa, arredondada ou cuneada, ápice agudo, obtuso, arredondado ou curtoacuminado. Inflorescências terminais, com ramos opostos a subopostos ou verticilados. Flores pequenas, diclinas; as estaminadas maiores que as pistiladas, glabras ou pilosas, 5-11 estames exsertos, filetes desiguais, filiformes, anteras com tecas iguais ou desiguais, pistilódio incluso, raro saliente; as pistiladas glabras a pilosas, ovário elipsoide, séssil, estilete cilíndrico, estigma penicelado, 4-9 estaminódios. Antocarpos elipsoides a globosos, vináceos a nigrescentes, glabros a levemente ferrugíneos.

Guapira é um gênero neotropical com aproximadamente 70 espécies (Bittrich \& Kühn 1993), distribuídas em diversos domínios fitogeográficos, nos Estados Unidos da América (Douglas \& Manos 2007), Costa Rica, Bolívia, Paraguai, Argentina e Brasil (Furlan \& Giulietti 2014). Para o Brasil, são reconhecidas 12 espécies de Guapira (Furlan \& Giulietti 2014), algumas distribuídas em praticamente todos os estados, exceto Roraima (Sá 2016), e todas representadas na Bahia, associadas à Mata Atlântica (florestas ombrófilas densas, florestas estacionais e restingas), Cerrado e Caatinga. 


\section{Chave para as espécies}

1. Lâmina foliar pilosa, velutina ou tomentosa, especialmente na face abaxial.

2. Gemas pubescentes, ferrugíneas, avermelhadas; lâmina foliar com base arredondada a obtusa; inflorescências ferrugíneas.

3. Inflorescências dispostas em cimeiras terminais congestas no ápice dos ramos; flores estaminadas ca. 3 mm compr.; antocarpos elipsoides

5. G. laxa

3'. Inflorescências dispostas em cimeiras terminais laxas no ápice dos ramos; flores estaminadas ca. $5 \mathrm{~mm}$ compr.; antocarpos globosos a oblongos .............................................................. 7. G. noxia

2'. Gemas hirsutas, castanhas; lâmina foliar com base aguda a atenuada; inflorescências castanhas ou pardas.

4. Ramos jovens hirsutos, castanhos a amarelados; folhas com margem plana

4. G. hirsuta

4'. Ramos jovens tomentosos, pardos a ferrugíneos; folhas com margem revoluta

11. G. tomentosa

1'. Lâmina foliar glabra em ambas as faces.

5. Folhas sésseis ou subsésseis, então pecíolo $1-5(-8) \mathrm{mm}$ compr.

6. Ramos jovens pubescentes; inflorescências com ramos predominantemente opostos a subopostos, seríceas ou pubescentes.

7. Pecíolo glabro; lâmina foliar com base arredondada a cordada, margem inteira; gemas 1-2 mm diâm.; flores estaminadas glabras

2. G. campestris

7'. Pecíolo piloso; lâmina foliar com base aguda a obtusa, margem repanda; gemas 2-3 mm diâm.; flores estaminadas incanas

3. G. graciliflora

6'. Ramos jovens glabros; inflorescências com ramos predominantemente verticilados a subverticilados, glabras a glabrescentes.

8. Brácteas ca. $2 \mathrm{~mm}$ compr.; flores pistiladas ca. $3 \mathrm{~mm}$ compr., incanas; antocarpos elipsoides, com coroa aberta ou prostrada

8. G. obtusata

8'. Brácteas 8-16 mm compr.; flores pistiladas ca. $2 \mathrm{~mm}$ compr., glabras; antocarpos globosos a oblongos, com coroa fechada ou ereta

10. G. pernambucensis

5'. Folhas pecioladas, pecíolo (4)5-20(-30) mm compr.

9. Gemas 2-4 mm diâm; inflorescências com ramos predominantemente opostos a subopostos.

10. Folhas com nervuras impressas na face abaxial; brácteas $2-4 \mathrm{~mm}$ compr., incanas na face abaxial, castanhas; antocarpos glabros a glabrescentes

1. G. areolata

10'. Folhas com nervuras salientes na face abaxial; brácteas 1-2 mm compr., pubescentes na face abaxial, ferrugíneas; antocarpos incanos

12. G. venosa

9'. Gemas ca. $1 \mathrm{~mm}$ diâm.; inflorescências com ramos predominantemente verticilados a subverticilados.

11. Lâmina foliar oblonga a oblongo-lanceolada; flores pistiladas $4-5 \mathrm{~mm}$ compr., pilosas na região basal; antocarpos estrigosos

6. G. nitida

11'. Lâmina foliar elíptica a elíptico-lanceolada; flores pistiladas 1-3 $\mathrm{mm}$ compr., glabras a glabrescentes na região basal; antocarpos glabros a glabrescentes 9. G. opposita

1. Guapira areolata (Heimerl) Lundell, Wrightia 4(2): 80. 1968.

Figuras 1 e $2 \mathrm{~A}-\mathrm{C}$.

Árvores ou arbustos, até $8 \mathrm{~m}$ alt.; ramos adultos retos, estriados quando secos, sempre glabros; gemas ca. $2 \mathrm{~mm}$ diâm., pubescentes, ferrugíneas a avermelhadas. Folhas com pecíolo 5-25 $\mathrm{mm}$ compr., glabro; lâmina 7-13(-18) × 4-6(-7) cm compr., elíptica a ovado-elíptica, base aguda a obtusa, ápice agudo a obtuso, margem inteira a repanda, plana, membranácea a cartácea, glabra em ambas as faces, nervuras impressas na face abaxial. Inflorescências com ramos predominantemente opostos a subopostos, 7-12 × 4-7 cm, dispostas em cimeiras terminais, congestas no ápice dos ramos, incanas, ferrugíneas; pedúnculo 2-6 $\mathrm{cm}$ compr.; brácteas 2-4 $\mathrm{mm}$ compr., incanas na face abaxial, castanhas. Flores (estaminadas e pistiladas) ca. $4 \mathrm{~mm}$ compr., pilosas, ferrugíneas. Antocarpos elipsoides a oblongos, 7-10 × 2-4 mm, atropurpúreos a nigrescentes, glabros a glabrescentes, geralmente com coroa aberta.
Guapira areolata é nativa do Brasil, ocorrendo também no Paraguai (Furlan \& Giulietti 2014). No Brasil, pode ser encontrada na Bahia, Distrito Federal, Goiás, Mato Grosso, Mato Grosso do Sul, Espírito Santo, Minas Gerais, Rio de Janeiro, São Paulo e Paraná (Sá 2016). E2, E6, E9, F6, F8, H8, I8: Mata Atlântica e ocasionalmente no Cerrado. Coletada com flores em julho, setembro e de dezembro a abril, e com frutos entre janeiro e maio.

Material selecionado - Alagoinhas, próximo à indústria Braspel, 1204'11.0”S, 38²0'09.0”'W, 120 m 24 abr. 2010 (fr.), E. Melo 8041 (HUEFS); Ibirapitanga, $22 \mathrm{~km}$ ao $\mathrm{N}$ de Itamarati na BR-101, depois 6,8 $\mathrm{km}$ a leste da rodovia para a torre da Embratel,

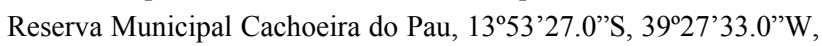
690 m s.n.m., 19 mar. 2003 (fl.), W.W. Thomas et al. 13463 (CEPEC, NY); Iraquara, Chapada Diamantina, Olhos d'Água, 12'13'51.0"S, 4124'41.0”'W, 8 fev. 2008 (fl.), A.F. Venâncio 108 (ALCB); Ituberá, Litoral Sul, fragmento do Corte Alto, Parcela 16,

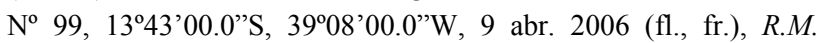
Valadão 324 (ALCB); Jussari, entrada a 7,5 km na rodovia JussariPalmeiras, fazenda Teimoso, $1,7 \mathrm{~km}$ da entrada, RPPN Serra do 
Teimoso, Parcela 41, Árvore 1183, 1509'16.0”S, 39³1'52.0”'W, 12 set. 2001 (fl.), J.G. Jardim et al. 3823 (CEPEC, HRCB); Lençóis, Chapada Diamantina, Serra da Chapadinha, 12 $26^{\prime} 00.0^{\prime \prime} \mathrm{S}$, 4127'00.0”'W, 1040 m s.n.m., 30 dez. 1994 (fl.), M.L. Guedes 1527 (ALCB); Luis Eduardo Magalhães, Oeste, $12^{\circ} 05^{\prime} 57.0^{\prime \prime} \mathrm{S}$ 45 46'10.0”', 760 m s.n.m., 20 set. 2003 (bot.), M.L. Guedes 10852 (ALCB); Porto Seguro, RPPN Estação Virasse, 16²0’00.0”S, 3908'00.0”W, 100 m s.n.m., 1 maio 2010 (fr.), G.M. Carvalho s.n. (CEPEC 140202); Rio de Contas, Chapada Diamantina, caminho para a Fazendola, $13^{\circ} 33^{\prime} 00^{\prime \prime}$, $41^{\circ} 48^{\prime} 00^{\prime \prime} \mathrm{W}, 8$ jul. 2012 (fl.), M.L. Guedes 20119 (ALCB); Salvador: Jardim Botânico de Salvador 1255'37'S, 38²5'37'W, 7 maio 2007 (fr.), E.P. Queiroz 2195 (HRB).

Material adicional selecionado - BRASIL. RIO DE JANEIRO: Petrópolis, 29 set. 1868 (fl.), A. Glaziou 3083 (síntipo P 712582).

Guapira areolata apresenta inflorescências com ramos predominantemente opostos a subopostos, folhas elípticas a ovado-elípticas com margem inteira a repanda, e nervura principal impressa na face abaxial. Esta última característica a diferencia de G. venosa, espécie próxima, mas que apresenta nervuras salientes na face abaxial.

2. Guapira campestris (Netto) Lundell, Wrightia 4(2): 80. 1968.

Figuras 1 e 2D-F.

Arbustos ou subarbustos, até $3 \mathrm{~m}$ alt.; ramos adultos levemente tortuosos, estriados quando secos, glabros, os jovens pubescentes, castanhos; gemas 1-2 mm diâm., pubescentes, ferrugíneas a avermelhadas. Folhas sésseis a subsésseis; pecíolo 1-5 $\mathrm{mm}$ compr., glabro; lâmina 3,5-5,5 × 2,5-3,0 cm, elíptica a ovadoelíptica, base arredondada a cordada, ápice arredondado a retuso, margem inteira, plana, cartácea a coriácea, glabra em ambas as faces, nervura principal impressa na face adaxial. Inflorescências com ramos predominantemente opostos a subopostos, 2,5-3,9 $\times 2$ $3,5 \mathrm{~cm}$, dispostas em cimeiras terminais, laxas, seríceas, ferrugíneas; pedúnculo 1,5-2 cm compr.; brácteas ca. $1 \mathrm{~mm}$ compr., incanas na face abaxial, ferrugíneas. Flores glabras, as estaminadas ca. 3,5 mm compr., as pistiladas ca. $2 \mathrm{~mm}$ compr. Antocarpos oblongos a elipsoides, 7-12 × 4-6 mm, atropurpúreos a nigrescentes, glabros, com coroa fechada ou ereta.

Endêmica do Brasil, ocorre no Distrito Federal, Goiás, Mato Grosso, Minas Gerais, Bahia e Piauí (Sá 2016). E1, E9, F6: Cerrado. Floresce de setembro a dezembro e frutifica de outubro a março.

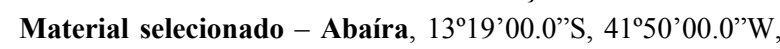
1350 m s.n.m., 21 dez. 1991 (fr.), R.M. Harley et al. H 50244 (NY,

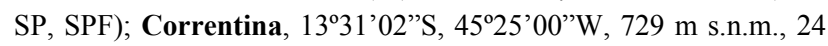
ago. 1995 (bot.), M.L. Fonseca et al. 8069 (HRCB); Entre Rios, $12^{\circ} 01^{\prime} 00.0^{\prime \prime}$, 38 $02^{\circ} 00.0^{\prime \prime} \mathrm{W}, 23$ mar. 2011 (fr.), A.V. Popovkin 851 (HUEFS); Luís Eduardo Magalhães, $12^{\circ} 13^{\prime} 00.0^{\prime} \mathrm{S}$, 45\%49'00.0”'W, 22 nov. 2010 (fl.), M.L. Guedes 17859 (ALCB); Mucugê, 1305'22”S, 41'22'42”'W, 24 jan. 2000 (fr.) L.P. Queiroz 5677 (HUEFS, CEPEC); Santa Cruz Cabrália, Estação Ecológica do Pau-Brasil, ca. $16 \mathrm{~km} \mathrm{~W}$ de Porto Seguro, 16²2'20”'S,
39¹0'54”'W, 26 nov. 1987 (fl., fr.) P.J.M. Maass et al. 7043 (CEPEC, NY); São Desidério, $12^{\circ} 42^{\prime} 20^{\prime \prime} \mathrm{S}, 45^{\circ} 48^{\prime} 50^{\prime \prime} \mathrm{W}, 7$ nov. 1997 (fr.), M.A. Silva et al. 3510 (RB).

Material adicional selecionado - BRASIL. PIAUÍ: Santa Rosa, set. 1839 (fl.), G. Gardner 2944 (lectótipo K 572730).

Guapira campestris é bem distinta das demais espécies da Bahia pelas folhas glabras, sésseis a subsésseis, com lâmina ovado-elíptica. Furlan \& Giulietti (2014) relataram a ocorrência de plantas anãs desta espécie para o Centro-Oeste, o que não foi observado na Bahia.

\section{Guapira graciliflora (Mart. ex J.A.Schmidt)} Lundell, Wrightia 4(2): 81. 1968.

Figuras 1, 2G-J e 10D.

Nome popular: farinha-seca (Santos 528 e Carvalho 5673).

Árvores ou arbustos, até $9 \mathrm{~m}$ alt.; ramos adultos levemente tortuosos, estriados quando secos, glabros, os jovens pubescentes, ferrugíneos; gemas 2-3 $\mathrm{mm}$ diâm., pubescentes, ferrugíneas a avermelhadas. Folhas subsésseis; pecíolo 3-5 mm compr., piloso, ferrugíneo; lâmina $5-10 \times 1,8-5,5 \mathrm{~cm}$, elíptica a elíptico-lanceolada, base aguda a obtusa, ápice obtuso a arredondado, margem repanda, plana, cartácea a coriácea, glabra em ambas as faces, nervuras salientes em ambas as faces. Inflorescências com ramos predominantemente opostos a subopostos, 5-8 × 3-6 $\mathrm{cm}$, em cimeiras terminais, laxas, pubescentes, ferrugíneas; pedúnculos 2-4,5 cm compr.; brácteas ca. $1 \mathrm{~mm}$ compr., pubescentes na face abaxial, ferrugíneas. Flores (estaminadas e pistiladas) ca. $3 \mathrm{~mm}$ compr., incanas, ferrugíneas. Antocarpos elipsoides, 5-10 × $2-$ $4 \mathrm{~mm}$, atropurpúreos a nigrescentes na maturidade, glabros, geralmente com coroa fechada.

Guapira graciliflora é endêmica do Brasil, ocorrendo nos estados da Bahia, Ceará, Maranhão, Pernambuco, Piauí, Rondônia, Tocantins, Goiás, Mato Grosso do Sul, Mato Grosso, Minas Gerais e São Paulo, além do Distrito Federal (Sá 2016). D2, D10, E6, E9, F6, F7, F8, G5, G7, G8, I8: Amazônia, Caatinga e Cerrado. Coletada com flores entre julho e março, e com frutos entre outubro e maio.

Material selecionado - Alagoinhas, Campus II/UNEB, 12'10'68"S 38²4'81"W, 8 jan. 2003 (fr.), N.G. Jesus 1619 (HUNEB); Apuarema, Concessão do Rio Tinto, 13⒌'46"S 3949'10"W, 5 mar. 2013 (fl.), L.Y.S. Aona et al. 2246 (HURB); Caetité, região dos Brejinhos das Ametistas, área da Bahia

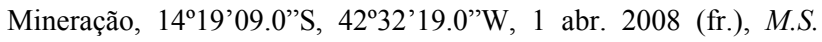
Mendes 540 (HUEFS); Conde, ida para Canguita, 11\%48'49.0"S, 37³6’38.2”W, 22 fev. 1992 (bot.), M.C. Ferreira \& H.P. Bautista 693 (HRB, HUEFS, HUNEB); Correntina, estrada entre a Velha da Galinha e Couro de Porco, 13³0'S, 40³5'W, 17 out. 1989 (fr.), R.C. Mendonça et al. 1573 (RB); Entre Rios, fazenda Rio do

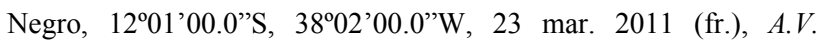
Popovkin 852 (HUEFS); Formosa do Rio Preto, rodovia Anel da

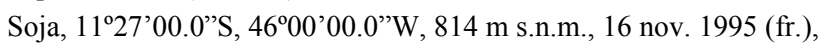
B.M.T. Walter et al. 2943 (HRCB); Ilhéus, Mata Esperança, 1446'05'S, 3904'09'W, 14 jan. 1995 (fl.), A.M. Carvalho et al. 


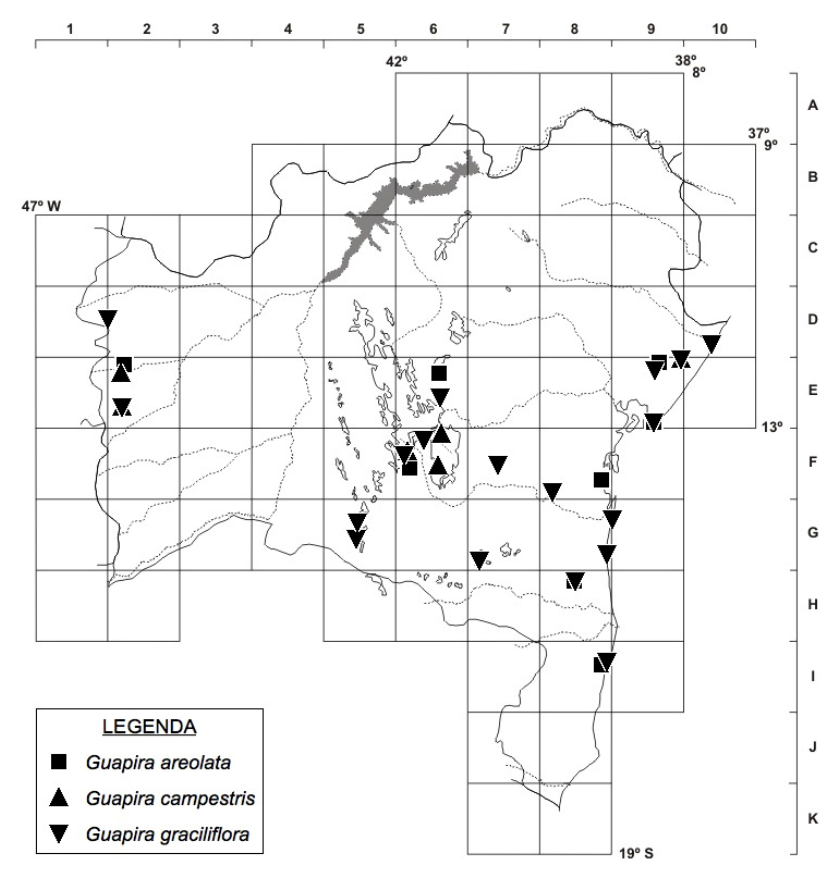

Figura 1. Distribuição de Guapira areolata, G. campestris e G. graciliflora no estado da Bahia.

5673 (CEPEC, HRCB); Itacaré, estrada Serra Grande, Km 20 a 23, 14¹6’39.0”S, 3859'48.1'W, 4 jul. 1996 (fl.), A.M. Carvalho 6236 (CEPEC, HRCB); Jussari, Serra do Teimoso, 7,5 km NW de Jussari na estrada para Palmeira, $2 \mathrm{~km} \mathrm{~S}$ da fazenda Teimoso, Reserva da Fazenda Teimoso, 31 jan. 1999 (fl.) W.W. Thomas et al. 11885 (MOBOT); Lençóis, arredores de Lençóis, 12³3'47.9”'S, 41²3'22.9”W, 400 m s.n.m., 1 nov. 1979 (fl.), S.A. Mori 12933 (CEPEC, NY, RB); Licínio de Almeida, Serra Geral, Serra do Salto, Trilha do Cascarrento, 14³3'59.0”S, 42³3'51.0”'W, 994 m s.n.m., 16 set. 2011 (bot., fl.), N. Roque 3314 (ALCB); Piatã, fazenda Beija-

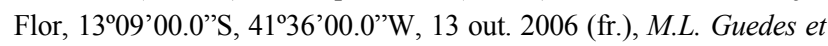
al. 12772 (ALCB, HUNEB); Porto Seguro, RPPN Estação Veracel, 16²17'31.8”S, 3904'48.3”W, 1 maio 2010 (fr.) G.M. Carvalho s.n. (CEPEC 140036); Rio de Contas, 13'22'07'S, 41'53'03'W, $1800 \mathrm{~m}$ s.n.m., 16 nov. 1996 (fr.), H.P. Bautista 4345 (ALCB, HRCB); Salvador, Jardim Botânico de Salvador, $12^{\circ} 55^{\prime} \mathrm{S}, 38^{\circ} 25^{\prime} \mathrm{W}, 5$ fev. 2004 (bot.), E.P. Queiroz 321 (HRB); Santa Cruz Cabrália, Estação Ecológica do Pau-Brasil, 16²3'S, 3908'W, 13 nov. 1985 (fr.), F.S. Santos 528 (CEPC, HRCB); São Desidério, Chapada de São Francisco, estrada de terra entre Roda Velha e Estiva, 1242'20.0”'S, 4548'50.0”'W, 7 nov. 1997 (fr.), F.C.A. Oliveira 860 (RB); Vitória da Conquista, arredores da cidade, 14 ${ }^{\circ} 51^{\prime} 58.0^{\prime \prime} \mathrm{S}, 40^{\circ} 50^{\prime} 21.8^{\prime \prime} \mathrm{W}, 16$ mar. 1995 (fl.), E. Melo \& F. França 1208 (HRCB, HUEFS).

Guapira graciliflora pode ser diferenciada das outras espécies do gênero por apresentar lâmina foliar elíptica a elíptico-lanceolada, com margem quase sempre repanda, além de ramos jovens e gemas pubescentes, ferrugíneas a avermelhadas.

4. Guapira hirsuta (Choisy) Lundell, Wrightia 4(2): 81. 1968.

Figuras 2K-M, 3 e 10E.

Nome popular: farinha-seca (Amorim 1144).

Árvores ou arbustos, até $8 \mathrm{~m}$ alt.; ramos adultos retos, estriados quando secos, glabros, os jovens hirsutos, castanhos a amarelados; gemas ca. $1 \mathrm{~mm}$ diâm., hirsutas, castanhas. Folhas com pecíolo piloso, castanho, 4-6 mm compr.; lâmina foliar 2-8(-11) $\times 1-$ $3(-5) \mathrm{cm}$, elíptica a elíptico-lanceolada, base aguda, ápice agudo a atenuado, margem inteira, plana, cartácea a membranácea, pilosa na face adaxial, castanha e pilosa na abaxial, nervura principal pilosa e impressa na face abaxial. Inflorescências com ramos predominantemente verticilados a subverticilados, 3$5(-8) \times 1-3(-6) \mathrm{cm}$, dispostas em cimeiras axilares ou terminais, laxas no ápice dos ramos, hirsutas, castanhas; pedúnculo 2-5 cm compr., brácteas ca. 1,5 $\mathrm{mm}$ compr., hirsutas na face abaxial, ferrugíneas. Flores estaminadas ca. $2 \mathrm{~mm}$ compr., glabras; as pistiladas ca. $3 \mathrm{~mm}$ compr., incanas, ferrugíneas. Antocarpos elipsoides, 5-7 $\times$ 2-3,5 $\mathrm{mm}$, atropurpúreos a nigrescentes na maturidade, glabros, geralmente com coroa aberta.

Guapira hirsuta é endêmica do Brasil, ocorrendo em todos estados do Sul e Sudeste, além de Goiás, Mato Grosso do Sul, Ceará, Maranhão, Paraíba, Alagoas, Acre e Pará (Sá 2016). D7, E6, E7, E8, E9, E10, F3, F6, F7, F8, G7, G8, H8, I8: Mata Atlântica, Caatinga e Cerrado. Floresce entre novembro e abril e frutifica entre janeiro e maio.

Material selecionado - Anguera, fazenda Retiro, ca. $18 \mathrm{~km}$ de Feira de Santana na Estrada do Feijão, sentido Ipirá, 1209'42.0"S, 39¹1'02.0”W, 400 m s.n.m., 22 maio 2007 (fr.), D. Cardoso 1979 (HUEFS); Apuarema, Concessão do Rio Tinto, 1353'33.0”S, 3941'54.0"W, 7 mar. 2013 (f1.), L.Y.S. Aona et al. 2294 (HURB, RB); Boa Nova, Parque Nacional Boa Nova, 14²3'19.5”'S, 4009'04.3”W, 2 mar. 2013 (fl.), L.Y.S. Aona et al. 2103 (HURB, RB); Cachoeira, Recôncavo Sul, vale dos rios Jacuípe e Paraguaçu. Morro Belo, $12^{\circ} 32^{\prime} 00.0^{\prime \prime} \mathrm{S}, 39^{\circ} 05^{\prime} 00.0^{\prime \prime} \mathrm{W}, 1$ nov. 1980 (bot.), L.S.S. Faria 954 (ALCB, HUEFS); Coribe, ca, $5 \mathrm{~km} \mathrm{~S}$ em estrada de terra que cruza pequeno ramal, que sai a $5.1 \mathrm{~km}$ E de Ponto d'água, a 24,4 $\mathrm{km} \mathrm{S}$ de São Félix do Coribe, na estrada para Coribe, $13^{\circ} 35^{\prime} 10.0^{\prime \prime} \mathrm{S}$, 44¹9'12.0”'W, 10 abr. 2007 (fl.), L.P. Queiroz 12722 (HUEFS); Cruz das Almas, Mata da Cazuzinha, 1240'12.0”'S, 3906'06.8”W, 22 mar. 2011 (fl.), S.S. Simões 23 (HURB); Entre Rios, Algodão, $12^{\circ} 10^{\prime} 00.0^{\prime \prime S} 37^{\circ} 58^{\prime} 00.0^{\prime \prime} \mathrm{W}, 120$ m s.n.m., 22 maio 2013 (fr.), A.V. Popovkin 1432 (HUEFS); Feira de Santana, fazenda Chapada, $12^{\circ} 14^{\prime} 00.5^{\prime \prime}$ S, 3900'03.3”'W, 131 m s.n.m, 6 abr. 2007 (fr.), E. Melo 4675 (HUEFS); Ilhéus, Mata da Esperança, próximo ao Banco da Vitória, na estrada Itabuna-Ilhéus, 1446’33.0”'S, 3905'24.0”'W, 105 m s.n.m., 28 maio 2000 (fr.), F. França et al. 3380 (HRCB, HUEFS); Itamaraju, assentamento Pedra Bonita, aproximadamente $20 \mathrm{~km}$ da rodovia vicinal de Itamaraju, sentido Jucuruçu, 16 50 '19.0'S, 39³7'53.0'”, 13 fev. 2000 (bot.), R.A.X.

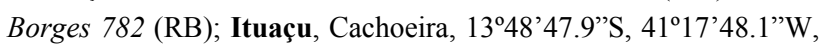
1 mar. 1992 (bot.), M.C. Ferreira 478 (RB); Jequié, fazenda Brejo Novo, a 10,5 km da avenida Otávio Mangabeira, entrado pela avenida Exupério Miranda no bairro do Mandacaru, 135' $41.0^{\prime \prime} \mathrm{S}$, 4006’34.0”'W, 4 abr. 2004 (fr.), G.E.L. Macedo 550 (HUNEB, RB); Morro do Chapéu, rio Ferro Doido, $11^{\circ} 37^{\prime} 15^{\prime}$ 'S, 40 $59^{\circ} 46^{\prime \prime} \mathrm{W}, 3$ mar. 1997 (fl.), P. Gassom 5972 (ALCB, CEPEC, HRB, HRCB, HUEFS, SP); Mucugê, $44 \mathrm{~km}$ da cidade de Mucugê, em direção a Brejo de Cima e João Correa (indo do entroncamento de Cascavel), 13¹8'31.0"S 41³6'12.0”W, 1128 m s.n.m., 25 jan. 2005 (fr.), R.M. 


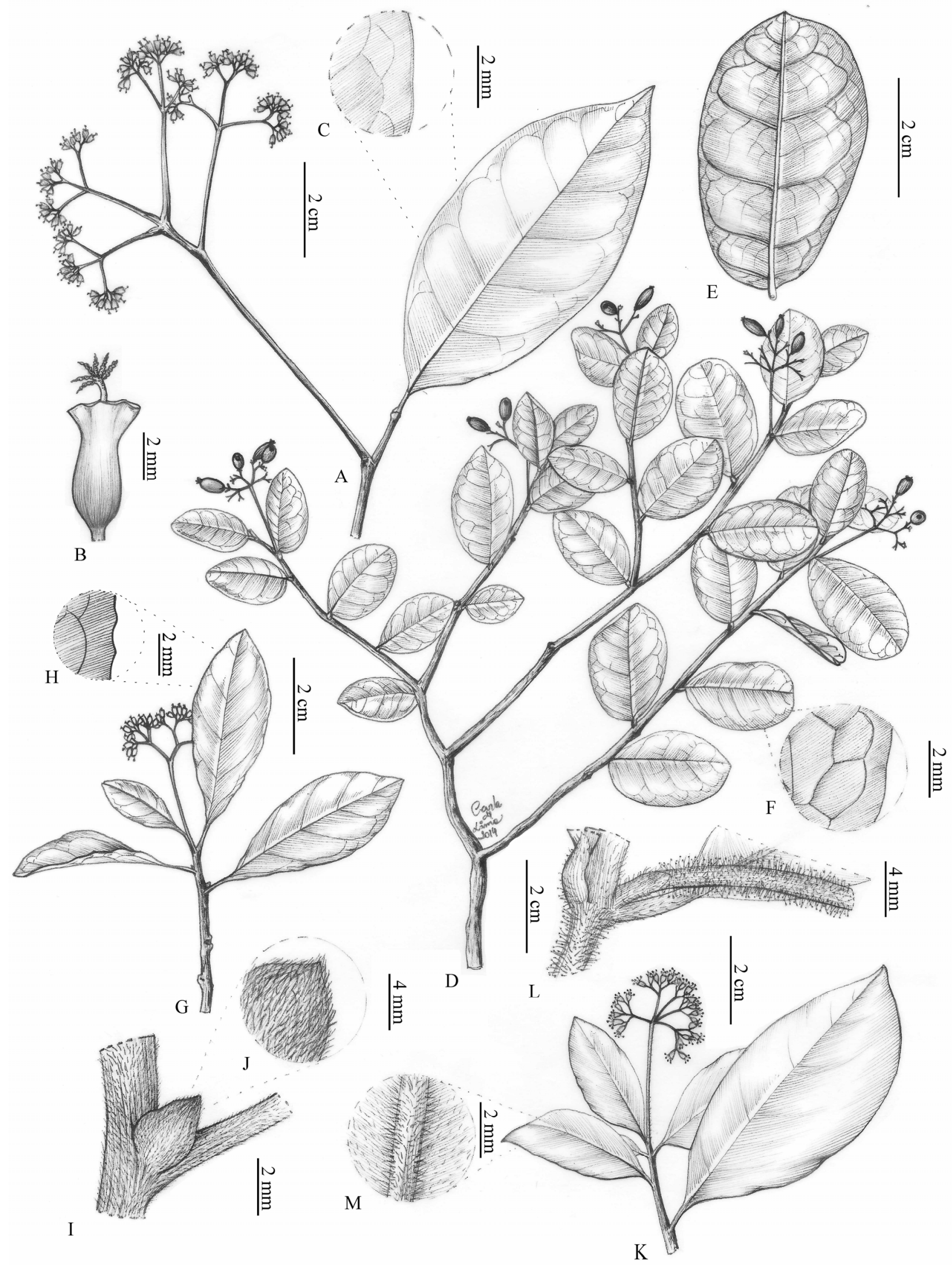

Figura 2. A-C. Guapira areolata: A- ramo com inflorescência; B- flor pistilada com estigma penicelado; C- detalhe da lâmina foliar com nervuras impressas, face abaxial. D-F. G. campestris: D- hábito; E- folha, face abaxial; F- detalhe da lâmina foliar evidenciando margem inteira, face adaxial; G-J. G. graciliflora: G- ramo com inflorescência; H- detalhe da lâmina foliar evidenciando margem repanda; I- ramo jovem evidenciando gema pubescente; J- detalhe da gema pubescente; K-M. G. hirsuta: K- ramo com folhas e inflorescência; L-ramo hirsuto; M- detalhe da lâmina foliar pilosa ao longo da nervura principal, face abaxial (A-C- Jardim 3823; D-F- Popovkin 851; G-JRoque 3314; K-M- Amorim 1144). 
Harley 55413 (HUEFS); Piatã, estrada de terra para a Mineração, 1307'14.0”'S, 4141'56.0”W, 1113 m s.n.m., 21 abr. 2014 (fl.), E. Melo 12819 (ALCB); Ruy Barbosa, Serra do Orobó, trilha para o pátio das orquídeas, $12^{\circ} 18^{\prime} 09.0^{\prime}$ 'S, 40²9’15.0”W, 19 dez. 2004 (fl.), L.P. Queiroz 9972 (HUEFS); Seabra, Mata de Cipó, 12²5'33.1”S, 4144'17.1”W, 900 m s.n.m., 23 fev. 1987 (fl., fr.) J.R. Pirani 1996 (K, SPF); Una, Reserva Biológica do Mico-Leão (IBAMA), entrada no $\mathrm{Km} 46$ da rodovia BA-001 Ilhéus-Una, 1509'S, 3905'W, 12 mar. 1993 (fl.), A.M. Amorim et al. 1144 (CEPEC, HRCB); Uruçuca, Parque Estadual de Serra do Conduru, Trilha da Bicuíba, 14²6'57.9”S, 3905'04.5”W, 10 mar. 2010 (f1.), L.A. Mattos-Silva 5187 (HUEFS).

Guapira hirsuta assemelha-se a $G$. tomentosa pela lâmina foliar elíptica, com ápice agudo e indumento na face abaxial, mas pode ser diferenciada pelo tipo de indumento (Marchioretto et al. 2011). O indumento de G. hirsuta é longo, ereto, macio e flexível, ao passo que $G$. tomentosa apresenta indumento relativamente curto, emaranhado e denso. Outro aspecto que diferencia as duas espécies é a margem da folha, que em $G$. tomentosa é revoluta e em $G$. hirsuta é plana.

5. Guapira laxa (Netto) Furlan, Bol. Bot. Univ. São Paulo 32(2): 173. 2014.

Figuras 3 e $5 \mathrm{~A}-\mathrm{C}$.

Nome popular: pau-piranha (Labouriau 931).

Árvores ou arbustos, até $8 \mathrm{~m}$ alt.; ramos adultos tortuosos, estriados quando secos, glabros, os jovens pubescentes, ferrugíneos, castanhos; gemas ca. $1 \mathrm{~mm}$ diâm., pubescentes, ferrugíneas, avermelhadas. Folhas com pecíolo 5-15(20) mm compr., incano, ferrugíneo; lâmina 3-10(-15) × 2-6(-9) cm, ovada a ovado-elíptica, base obtusa, ápice cuneado a agudo, margem repanda, levemente revoluta, membranácea a subcoriácea, castanha e incana na face adaxial, ferrugínea e tomentosa na abaxial, pilosa na nervura principal, nervuras salientes na face abaxial. Inflorescências com ramos predominantemente opostos a subopostos, 1-3 $\times$ 1-2 cm, em cimeiras terminais, congestas no ápice dos ramos, tomentosas, ferrugíneas; pedúnculo $0,5-2,5 \mathrm{~cm}$ compr.; brácteas ca. $2 \mathrm{~mm}$ compr., tomentosas na face abaxial, ferrugíneas. Flores incanas, ferrugíneas, as estaminadas ca. $3 \mathrm{~mm}$ compr., as pistiladas ca. $2 \mathrm{~mm}$ compr. Antocarpos elipsoides, 9-13 × 3-5 mm., atropurpúreos a nigrescentes na maturidade, levemente pilosos, ferrugíneos, enrugados quando secos, geralmente com coroa fechada.

Guapira laxa é endêmica do Brasil, ocorrendo em quase todos estados do Nordeste (exceto no Maranhão), além de Minas Gerais e possivelmente Rio de Janeiro, onde dois espécimes foram supostamente coletados por A. Glaziou (Furlan \& Giulietti 2014). B5, B6, B9, C8, D6, E7, E8, E8, F6, F7, I8: Caatinga. Coletada com flores entre julho e novembro e em fevereiro, e com frutos entre setembro e dezembro e em março.

Material selecionado - Cachoeira, 12²3'00.0'S, 3905'00.0”'W, 12 m s.n.m., set. 1980 (bot.), Grupo Pedra do Cavalo 720 (HUEFS); Camaçari, 12²9'00.0”S, 38¹8'00.0”W, 9 dez. 1982 (fr.) L.R. Noblik 2424 (HUEFS); Canudos: Toca Velha, Estação
Biológica de Canudos, (sede Biodiversitas), 1001'58.0”S, 3909'00.0”'W, 29 out. 2001 (bot.), L.P. Queiroz 7021 (HUEFS); Casa Nova, $09^{\circ} 28^{\prime} 00.0^{\prime \prime} \mathrm{S}, 41^{\circ} 15^{\prime} 00.0^{\prime \prime} \mathrm{W}, 10$ set. 1981 (fl.), L.M.C. Gonçalves 217 (HRB, RB, SPF); Cruz das Almas, Mata da Cazuzinha, 1240'12.0'S, 3906’06.8”W, 5 mar. 2013 (fr.), G. Costa 816 (HUEFS); Feira de Santana, $12^{\circ} 15^{\prime} 00.0^{\prime \prime}$ 'S, 38 $8^{\circ} 58^{\prime} 00.0^{\prime \prime} \mathrm{W}, 15$ fev. 1984 (bot.), L.R. Noblick 2934 (HUEFS); Glória, Serra de Itaparica, 0906'20.0”S, 38¹9'05.0”W, 312 m s.n.m., 17 jul. 2007 (bot.), A.S. Conceição 1101 (HUEFS); Itaberaba, morro Itaberaba, $12^{\circ} 30^{\prime} 02.0^{\prime \prime} \mathrm{S}, 40^{\circ} 04^{\prime} 59.0^{\prime \prime} \mathrm{W}, 270 \mathrm{~m}$ s.n.m., s.d. (bot.), A.O. Moraes 73 (HUEFS); Itatim, Morro do Agenor, encosta do Morro, 12'42'42.0”'S, 3946'12.0”'W, 370 m s.n.m., 31 out. 2004 (fl.), E. Melo 3728 (HUEFS, INPA); Maracás, rodovia BA-026, $6 \mathrm{~km}$ a SW de Maracás, 13²6'28.0”'S, 40²5'50.9'W, 17 nov. 1978 (fl.), S.A. Mori 11103 (RB); Milagres, divisa com Brejões, rio Brejões, 1255'56.0”'S, 3953'59.0”'W, 8 set. 2012 (fr.), E. Melo 11495 (HUEFS); Morro do Chapéu, Piemonte da Diamantina, caminho

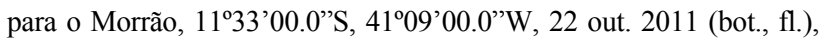
M.L. Guedes 19345 (ALCB); Paulo Afonso: 09²4'22.0"S, 38'12'52.9'W, 10 abr. 1952 (bot.), M.S. Labouriau 931 (RB);

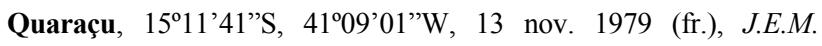
Brazão 141 (HRB, SPF); Remanso, divisa com Piauí, ca. $30 \mathrm{~km}$ de Remanso, 09²3'14.0”'S, 42²1'36.0”W, 500 m s.n.m., 28 dez. 2001 (fr.), T.S. Nunes 682 (HUEFS); Santa Cruz Cabrália, antiga rodovia que liga a Estação Ecológica do Pau-Brasil a Santa Cruz, 5-7 km a NE da Estação, 16²3'00.0”'S, 3908'00.0”'W, 5 jul. 1979 (fl.), S.A. Mori 12093 (RB); Santa Teresinha: 1246'18.8”S 39³1'23.9”'W, 18 jun. 1993 (bot.), L.P. Queiroz 3249 (HUEFS).

Guapira laxa caracteriza-se pelas folhas com margem repanda, levemente revoluta, pelas inflorescências dispostas em cimeiras terminais, congestas no ápice dos ramos e pelo antocarpo elipsoide. Tem distribuição restrita ao Nordeste e Sudeste, ocorrendo predominantemente em áreas de Caatinga (Furlan \& Giulietti 2014; Sá 2016).

6. Guapira nitida (Mart. ex J.A.Schmidt) Lundell, Wrightia 4(2): 82. 1968.

Figuras 3 e 5D-E.

Árvores ou arbustos, até $10 \mathrm{~m}$ alt.; ramos adultos retos, estriados quando secos, glabros, os jovens glabros ou glabrescentes; gemas ca. $1 \mathrm{~mm}$ diâm., pubescentes, ferrugíneas a avermelhadas. Folhas com pecíolo 6-10 mm compr., glabro; lâmina 7-13(-18) × 3-5(7) cm, oblonga a oblongo-lanceolada, base obtusa, ápice agudo a acuminado, margem inteira, plana, subcoriácea a membranácea, glabra em ambas as faces, nervura principal inconspícua. Inflorescências com ramos predominantemente verticilados a subverticilados, 5-10 × 3-8 cm, cimeiras terminais, frequentemente congestas no ápice dos ramos, incanas, ferrugíneas; pedúnculo atropurpúreo, 3-7 cm compr.; brácteas ca. 1,5 mm compr., incanas na face abaxial, ferrugíneas. Flores estaminadas ca. $5 \mathrm{~mm}$ compr., incanas na região basal, ferrugíneas, as pistiladas 4-5 $\mathrm{mm}$ compr., pilosas na região basal. Antocarpos elipsoides, 6-10 × 2-4 $\mathrm{mm}$, atropurpúreos a nigrescentes na maturidade, estrigosos, ferrugíneos; enrugados quando secos, geralmente com coroa aberta. 


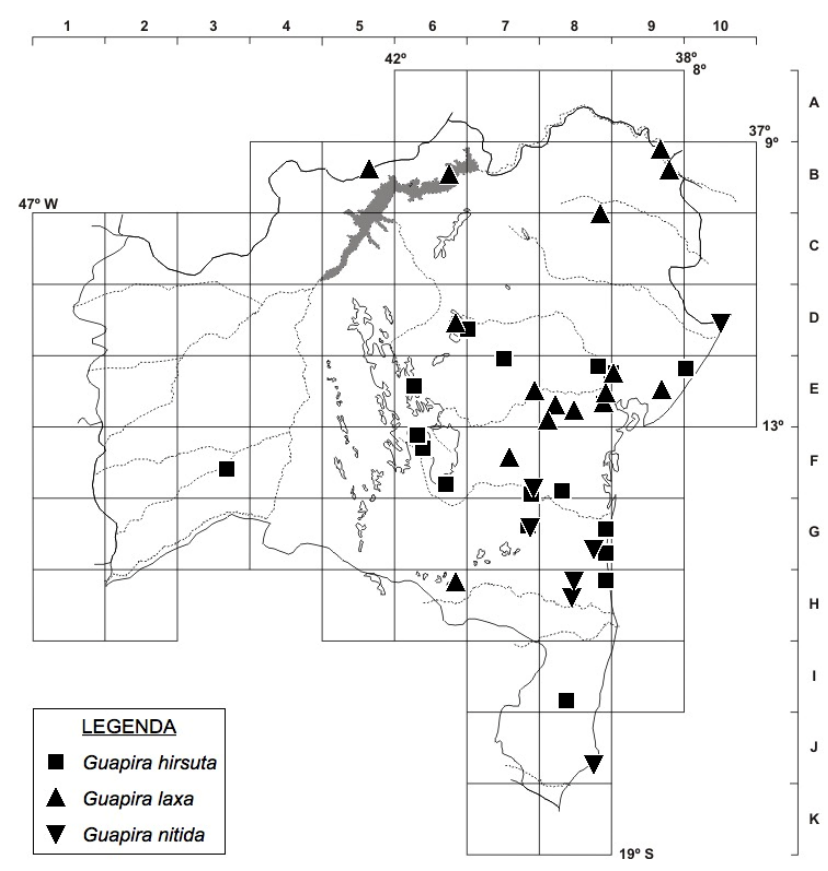

Figura 3. Distribuição de Guapira hirsuta, G. laxa e G. nitida no estado da Bahia.

Guapira nitida é nativa, endêmica do Brasil, ocorrendo em São Paulo, Rio de Janeiro, Espírito Santo e Bahia (Sá 2016). D10, F7, G7, G8, H8, J8: Mata Atlântica. Coletada com flores em março e entre julho e novembro, e com frutos entre outubro e dezembro e em março.

Material selecionado - Boa Nova, ramal para a fazenda Liberdade, Setor Sul, 14²4'45.0”S, 4007'11.0”'W, 917 m s.n.m., 7 jan. 2013 (fr.), L.Y.S. Aona et al. 1954 (FUEL, HURB, RB); Camacan, RPPN Serra Bonita, 9,7 km W de Camacan na estrada para Jacareci, daí $6 \mathrm{~km} \mathrm{SW}$ na estrada para RPPN Serra Bonita e torre, 15²3'30.0”'S, 39³3'55.0”'W, 835 m s.n.m., 31 ago. 2008 (fl.), A.M. Amorim et al. 7708 (CEPEC, RB); Caravelas, extremo sul da Bahia, 17²4'54.8”, 39¹5'56.9”'W, 1 mar. 2011 (bot.), H.M. Dias 285 (RB); Ilhéus, Itabuna, depois do Salobrinho, ramal à direita, sentido Rio do Braço, 1442'30.0”'S, 39¹5'13.0”W, 24 nov. 2010 (fl.), L. Daneu 456 (RB); Jandaíra, badia-fazenda Areia Branca

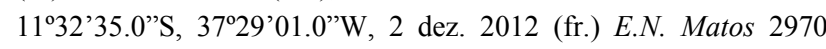
(ALCB); Jequié, fazenda Brejo Novo, 1351'27.0"S, 4005'01.0”W, 10 nov. 2004 (bot.), G.E.L. Macedo \& J.L. Paixão 1817 (HUESB, HURB, RB); Jussari, RPPN Serra Teimoso, entrada a 7,5 km da rodovia Jussari - Palmeira, fazenda Teimoso, $1,7 \mathrm{~km}$ da entrada, 1509'16.0”S, 39³1'52.0”'W, 17 set. 2004 (fl.), A.M. Amorim, 4266 (CEPEC, HUEFS, RB).

Guapira nitida é caracterizada pelos ramos jovens glabros a glabrescentes, pelas folhas glabras em ambas as faces mesmo quando novas, as adultas relativamente grandes e carnosas, e pelas inflorescências com ramos predominantemente verticilados a subverticilados.

7. Guapira noxia (Netto) Lundell, Wrightia 4(2): 83. 1968.

Figuras 4, 5G-I e 10F.

Árvores ou arbustos, até $7 \mathrm{~m}$ alt.; ramos adultos tortuosos, com súber pronunciado e espesso, glabros, os jovens, incanos, ferrugíneos, avermelhados; gemas 2-4 $\mathrm{mm}$ diâm., pubescentes, ferrugíneas, avermelhadas. Folhas com pecíolo (2-)5-8(-30) $\mathrm{mm}$ compr., incano, ferrugíneo; lâmina 6-10 × 4-7 cm, elíptica a ovadoelíptica, base arredondada a obtusa, ápice arredondado a obtuso, margem sinuada, levemente revoluta, membranácea, ferrugínea na face adaxial, ferrugínea e tomentosa na abaxial, nervura principal pilosa, ferrugínea e impressa na face abaxial. Inflorescências com ramos predominantemente opostos a subopostos, 4-7(-11) × 3-6(-9) cm, dispostas em cimeiras terminais, laxas no ápice dos ramos, tomentosas, ferrugíneas; pedúnculo verde, 2-4(-6) $\mathrm{cm}$ compr.; brácteas ca. $2 \mathrm{~mm}$ compr., pubescentes na face abaxial, ferrugíneas. Flores incanas, ferrugíneas, as estaminadas ca. $5 \mathrm{~mm}$ compr., as pistiladas ca. $3 \mathrm{~mm}$ compr. Antocarpos globosos a oblongos, 7-12 × 3-4 mm, atropurpúreos a nigrescentes na maturidade, levemente pilosos, ferrugíneos, enrugados quando secos, geralmente com coroa fechada ou prostrada.

Guapira noxia é endêmica do Brasil, citada apenas para os estados de São Paulo, Minas Gerais, Distrito Federal, Goiás, Mato Grosso e Mato Grosso do Sul (Furlan 2004; Furlan et al. 2008; Sá 2016), sendo registrada pela primeira vez para o estado da Bahia e para o Nordeste aqui. D2, E1, F2, F6: Cerrado. Floresce de julho a dezembro e pode ser encontrada com frutos entre outubro e janeiro.

Material selecionado - Contendas do Sincorá, 1348'04.0”S, 4102'36.0”W, 24 out. 1978 (fr.), A.P.P. Araújo 105 (HRB); Correntina, caminho para Santa Maria da Vitória,

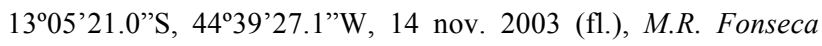
123 (HRB); Formosa do Rio Preto, $11^{\circ} 00^{\prime} 48.5^{\prime \prime} \mathrm{S}$, $45^{\circ} 12^{\prime} 39.8^{\prime \prime} \mathrm{W}, 24$ jul. 1993 (bot.), B.M.T. Walter et al. 2783 (HRCB); Jaborandi, $30 \mathrm{~km}$ ao norte da BA-172, 133' $49.5^{\prime}$ 'S, 44⒉ $54.3^{\prime \prime} \mathrm{W}, 3$ set. 2007 (fl.), T. Ribeiro 4682 (HRB); Luis Eduardo Magalhães, $12^{\circ} 09^{\prime} 52.2^{\prime \prime} \mathrm{S} 46^{\circ} 12^{\prime} 55.0^{\prime \prime} \mathrm{W}, 13$ set. 2005 (bot.), E.P. Queiroz 542 (HRB).

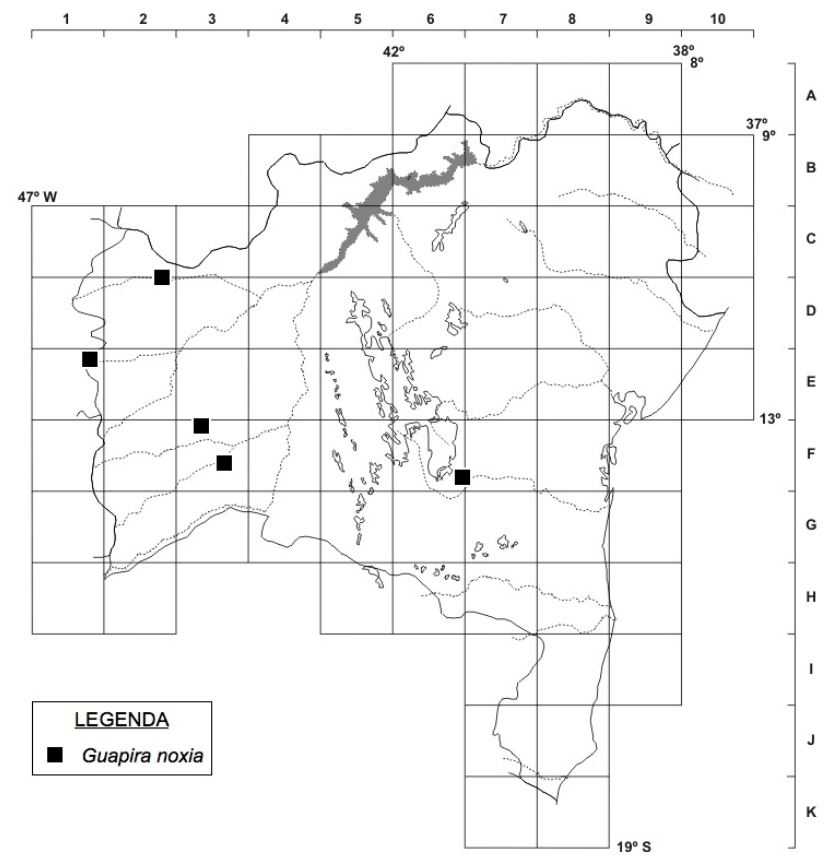

Figura 4. Distribuição de Guapira noxia no estado da Bahia. 
Guapira noxia assemelha-se a G. laxa pelos ramos adultos tortuosos a levemente tortuosos e pelas gemas indumentadas, ferrugíneas, avermelhadas. Típica do cerrado, é caracterizada pelas inflorescências dispostas em cimeiras terminais, congestas no ápice dos ramos e pelos antocarpos elipsoides.

8. Guapira obtusata (Jacq.) Little, Phytologia 17(5): 368.1968.

Figuras 5J-L, 6 e 10A.

Nome popular: maria-farinha-da-folha-miúda (Jesus 950), pau-de-açúcar (Ferreira 888), joão-mole (Farias 177)

Árvores ou arbustos, até $8 \mathrm{~m}$ alt.; ramos adultos tortuosos, estriados quando secos, glabros, os jovens glabros; gemas ca. $1 \mathrm{~mm}$ diâm., levemente pilosas, ferrugíneas. Folhas subsésseis; pecíolo 1-3(-8) $\mathrm{mm}$ compr., piloso, ferrugíneo; lâmina 3-8(-12) × 3,5-6(9) $\mathrm{cm}$, ovada a ovado-elíptica, base aguda a cuneada, ápice arredondado a cuneado, margem inteira a levemente repanda, plana, cartácea a coriácea, glabra em ambas as faces, nervuras não salientes. Inflorescências com ramos predominantemente verticilados a subverticilados, $1-4(-7) \times 1-2,5(-5) \mathrm{cm}$, dispostas em cimeiras terminais, congestas no ápice dos ramos, glabras a glabrescentes; pedúnculo 0,52,0(-4) cm compr.; brácteas ca. $2 \mathrm{~mm}$ compr., incanas na face abaxial, castanhas. Flores (estaminadas e pistiladas) ca. $3 \mathrm{~mm}$ compr., incanas. Antocarpos elipsoides, 5-9 × 2-5 $\mathrm{mm}$, atropurpúreos a nigrescentes na maturidade, incanos, geralmente com coroa aberta ou prostrada.

Guapira obtusata é nativa, mas não endêmica do Brasil, podendo ser encontrada também na América do Norte e América Central. No Brasil, ocorre em Santa Catarina, em todos os estados do Sudeste, em Pernambuco, Ceará, Sergipe e Bahia (Sá 2016). D6, E6, E9, F8, G7, I8: Cerrado e ocasionalmente na Mata Atlântica. Encontrada com flores entre setembro e maio e com frutos entre outubro e junho.

Material selecionado - Alagoinhas, povoado da Mangueira $12^{\circ} 11^{\prime} 06.0^{\prime \prime}$, $38^{\circ} 25^{\prime} 41.0^{\prime \prime} \mathrm{W}, 30$ out. 2008 (bot.), N.G. Bastos et al. 79 (HUNEB); Boa Nova, Parque Nacional Boa Nova, 14¹9'59'S, 40¹2'30”W, 2 mar. 2013 (fr.), L.Y.S. Aona et al. 2093 (FUEL, HURB, RB); Conde, Fazenda do $\mathrm{Bu}$, Mata do Fundão I, $11^{\circ} 48^{\prime} 49.0$ ”'S, 37³6’38.2”W, 2 fev. 1996 (bot.), M.C. Ferreira 888 (HRB, HUNEB, RB); Bonito, Chapada Diamantina, estrada para

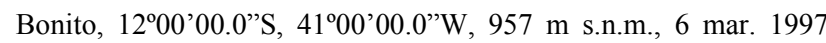
(fr.), P. Gasson et al. 6101 (ALCB, HRCB); Entre Rios, RPPN Fazenda Lontra/Saudade, 11 53 '21.8”S, 3804'12.3”'W, 7 maio 1999 (bot.), N.G. Jesus et al. 950 (HUNEB); Ibicoara, fazenda Ponte do Roxo $12^{\circ} 49^{\prime} \mathrm{S}, 41^{\circ} 19^{\prime} \mathrm{W}, 2$ dez. 1986 (fr.), J.D.C.A. Ferreira 408 (HRB); Jacobina, antena do Bairro dos Índios, $11^{\circ} 10^{\prime} 58.1$ ”S, 40³0'20.5”W, 26 jun. 1999 (fr.), F. França 3155 (HRCB, HUEFS); Morro do Chapéu, ca. $5 \mathrm{~km} \mathrm{~S}$ do Morro do

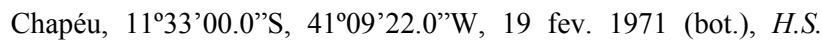
Irwin 32555 (MBM, NY, RB, UB); Mucugê, Chapada Diamantina, rodovia BA-142, $\mathrm{Km} 87$, em frente à torre da Central Repetidora de Mucugê/Telebahia, 1257'30.0”S, 41'19'14.0”'W, 1168 m s.n.m., 23 set. 2005 (bot. fl.), L.C.S. Giordano 2719 (HUNEB, RB); Pojuca, fazenda Cosme e Damião 12²2'05.7'S, 3809'51.3”W, 5 out. 2009 (bot.), E.P. Queiroz 4004 (HRB); Porto Seguro, reserva Florestal de Porto Seguro, 26 abr. 1988 (fl.), G.L. Farias 177 (HRCB); Santa Cruz Cabrália, ramal para fazenda Aida Hartman, 16² 16'15.5"S, 3901'35.6”W, 50 m s.n.m., 14 out. 1983 (bot.), G. Martinelli 9655 (RB); Wenceslau Guimarães, Estação Ecológica Estadual Nova Esperança; trilha da água vermelha, 1334'43”S, 3942'55'W, 450 m s.n.m., 14 out. 2012 (fl.), W. Milliken et al. 5085 (FURB, HURB, $\mathrm{RB})$.

Guapira obtusata pode ser reconhecida pelas inflorescências glabras a glabrescentes, folhas com pecíolo curto, muitas vezes piloso, ferrugíneo, e lâmina com base aguda a cuneada, ápice arredondado a agudo, margem inteira a levemente repanda e plana, características marcantes da espécie.

9. Guapira opposita (Vell.) Reis, F1. Ilustr. Catarin. 1: 32. 1970.

Figuras 6, 9A, B e 10B.

Nome popular: maria (Jesus 838), farinha-seca (Stradmann 1065).

Árvores ou arbustos, até $12 \mathrm{~m}$ alt.; ramos sempre glabros, os adultos retos; gemas ca. 1 mm diâm., ferrugíneas, levemente pilosas. Folhas com pecíolo (5)15-30 mm compr., glabro; lâmina (4-)7-12 × (1-)2-5 $\mathrm{cm}$, elíptica a elíptico-lanceolada, base aguda, ápice agudo a cuneado, curto acuminado, margem inteira, plana, cartácea a membranácea, glabra em ambas as faces, nervura principal inconspícua na face abaxial. Inflorescências com ramos predominantemente verticilados a subverticilados, (4-)6-10 × (2-)2-8 cm, dispostas em cimeiras terminais, laxas, incanas, ferrugíneas; pedúnculo atropurpúreo, 2-6 cm compr.; brácteas ca. 1,5 mm compr., incanas na face abaxial, ferrugíneas. Flores estaminadas ca. $4 \mathrm{~mm}$ compr., glabras, as pistiladas 1-3 mm compr., glabras a glabrescentes na região basal. Antocarpos globosos a oblongos, 5-8 × 2-5 mm, atropurpúreos a nigrescentes, glabros a glabrescentes, geralmente com coroa aberta.

Guapira opposita é nativa do Brasil, também encontrada na Bolívia, Paraguai, Guiana Francesa e Suriname (Furlan 2004; Furlan \& Giulietti 2014). É a espécie de Guapira mais amplamente distribuída no país, ocorrendo em todas as Regiões e na maioria dos estados do Brasil (Sá 2016). B9, E8, E10, F6, F7, F8, G7, G8, H8, I8, J8: Mata Atlântica e ocasionalmente Cerrado. Coletada com flores entre setembro e novembro e também entre fevereiro e maio e com frutos entre outubro e dezembro, em fevereiro, e entre maio e agosto.

Material selecionado - Almadina, Serra do Concovado, rodovia Almadina-Coaraci, ca. 5 km., 1442'13.0'S, 39³6'09.0”'W, 300 m s.n.m., 19 mar. 2006 (fr.), J.L. Paixão 891 (CEPEC, RB); Apuerama, Concessão da Rio Tinto, 1353'46.0'S, 3941'10.0”W, 5 mar. 2013 (fl.), L.Y.S. Aona 2234 (HURB); Cachoeira, $12^{\circ} 32^{\prime} 00.0^{\prime}$ 'S, 3905'00.0”'W, 100 m s.n.m., out. 1980, Grupo Pedra do Cavalo 861 (HRB); Camacan, RPPN Serra Bonita, 9,7 km W de Camacan na estrada para Jacareci, daí $6 \mathrm{Km} \mathrm{SW}$ na estrada para 


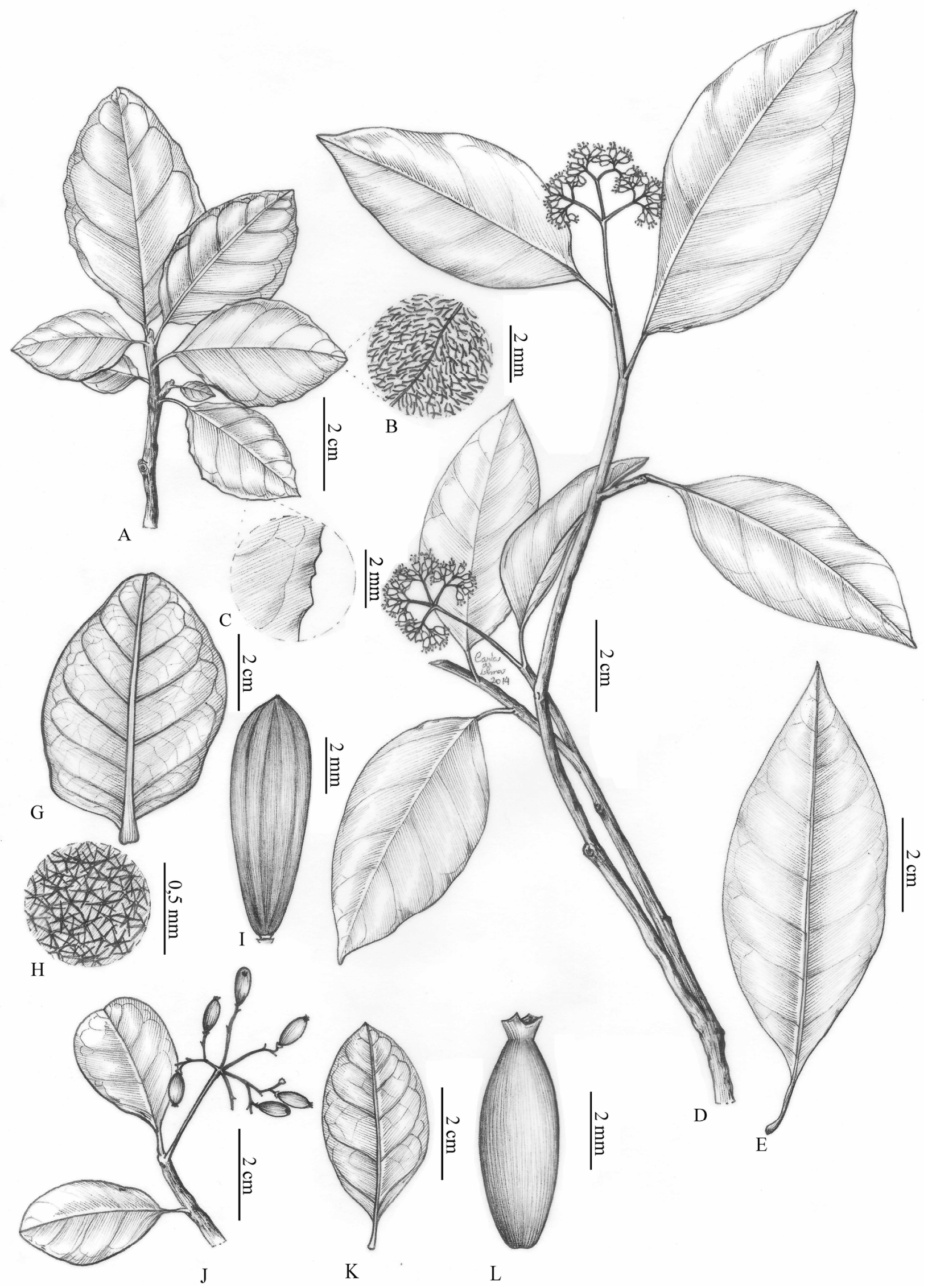

Figura 5. A-C. Guapira laxa: A- ramo com folhas; B- detalhe da lâmina foliar tomentosa, face abaxial; C- detalhe da lâmina foliar evidenciando margem repanda. D, E. G. nitida: D- hábito; E- folha, face abaxial. G-I. G. noxia: G- lâmina foliar, face abaxial; H- detalhe da lâmina foliar tomentosa e emaranhada, face abaxial; I- antocarpo com coroa fechada voltada para baixo, vista lateral; J-L. G. obtusata: J- ramo com frutos; K- lâmina foliar, face abaxial; L- antocarpo com coroa aberta voltada para cima, vista lateral (A-C- Costa 816; D, E- Aona 1954; G-I- Araújo 105; J-L- Gasson 6101). 


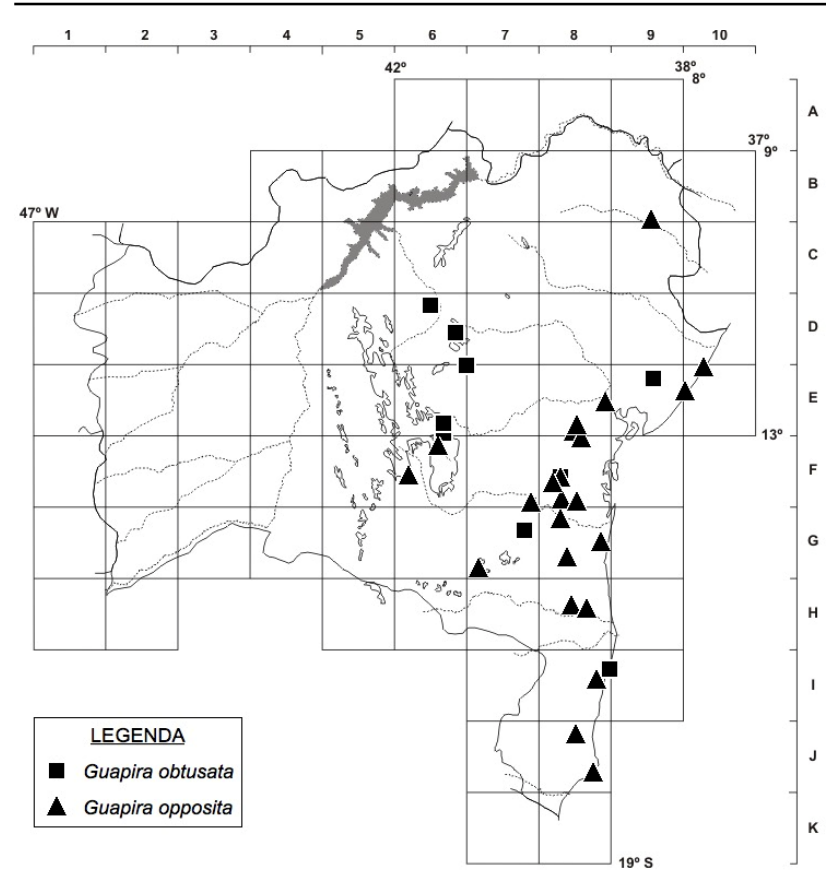

Figura 6. Distribuição de Guapira obtusata e G. opposita no estado da Bahia.

RPPN Serra Bonita e Torre, 15²3'30.0”'S, 39³3'55.0”'W, $835 \mathrm{~m}$ s.n.m., 24 jun. 2008 (fr.), A.M. Amorim 7489 (CEPEC, RB); Caravelas, Ilha do Cassurubá, na região conhecida como Telhas, próximo à região de Barra Velha, distrito de Nova Viçosa, 17\%43'54.8”S, 39¹5'56.9'W, 1 mar. 2011 (bot.), H.M. Dias 284 (RB); Conde, Fazenda do $\mathrm{Bu}$, trilha 2 da mata da maré, $12^{\circ} 02^{\prime} \mathrm{S}$ 37²43'W, 31 maio 1995 (fr.), L.N. Silva \& M.C. Ferreira 53 (HUNEB, RB); Entre Rios, RPPN Fazenda Lontra/Saudade, 14 mar. 1999 (bot.), N.G. Jesus et al. 838 (HUNEB); Ibirapitanga, Serra do Papua, APA do Pratigi, descida do córrego 1, subida pelas parcelas 7 e 8 , trilha principal, $13^{\circ} 55^{\prime} 10.0^{\prime}$ 'S, 39² $8^{\prime} 06.0^{\prime \prime} \mathrm{W}, 14$ mar. 2013 (fl.), L.Y.S. Aona et al. 2510 (HURB, RB); Jeremoabo, Baixa dos Quelés, 0958'00.0”'S, 38²6'16.0”W, 17 out. 2009 (fl.), E. Melo 6629

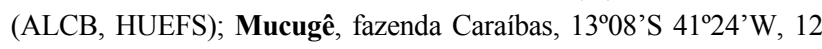
dez. 2004 (fr.), M.T.S. Stradmann \& P. Castilho 1065 (ALCB, HRCB); Itacaré, Litoral Sul, Mata da Antena, 14¹0'02.0”'S, 39'42'40.0”'W, 15 set. 2008 (fl.), C.H. Ramos 349 (ALCB); Itanagra, Litoral Norte, Núcleo Agroecológico, 12²2'32.0”S, 3758'51.0”W, 30 m s.n.m., 1 fev. 2009 (fl., fr.), A.R.S. Prates 292 (ALCB); Jaguaquara, distrito de Baixão do Ipiuna, 1340'05.0”'S, 3948'57.0”'W, 9 out. 2012 (fr.), D.C. Zappi 3380 (FUEL, RB); Prado, Parque Nacional do Descobrimento, entrada à esquerda no $\mathrm{Km} 8$ da estrada principal que atravessa o Parque, $17^{\circ} 11^{\prime} 00.0^{\prime} \mathrm{S}$, 39²0’00.0’W, 150 m s.n.m., 3 nov. 2009 (fl.), L. Daneu et al. 195 (CEPEC, RB); Porto Seguro, trilha da RPPN Estação Veracel, ao lado da plataforma, que sai na Polícia Rodoviária Federal de Porto Seguro, 16²5'09.0”S, 39¹2'08.0”'W, 18 mar. 2010 (fl.), L. Daneu et al. 309 (CEPEC, RB); Rio de Contas, Chapada Diamantina, caminho

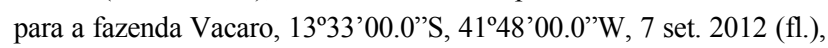
M.L. Guedes 20102 (ALCB); Salvador, fragmento Canabrava na paralela, 12 56 'S, 39 $31^{\prime} \mathrm{W}, 5$ abr. 2011 (bot.), M.L. Guedes et al. 18433 (ALCB, HRB); Santa Cruz Cabrália, 7 km NE da antiga rodovia ESPAB-Cabrália, $12 \mathrm{~km} \mathrm{NW}$ de Porto Seguro, 16²3'00.0”'S, 3908'00.0'W, 100 m s.n.m., 14 ago. 1979 (fr.), S.A. Mori 12704 (CEPEC, HRCB, HUEFS, MBM, RB); Santa Luzia, Serra da Onça,
10,8 km NE de Santa Luzia (30 km SW de Una), 15²5’04.8”S, 39²0'03.1"W, 21 nov. 1996 (fr.), W.W. Thomas 11361 (HRCB, NY, RB); Santa Terezinha, Pedra Branca, Serra da Jiboia, Morro da Pioneira, 1251'13.0"S, 39²8'32.0”'W, 700 m s.n.m., 2 nov. 2001 (fl.), J.G. Carvalho-Sobrinho et al. 61 (HRCB, HUEFS); São Miguel das Matas, fazenda Engenho da Lama (proprietário Genival Lucas), ca. $4,5 \mathrm{~km}$ ao $\mathrm{S}$ da cidade, $13^{\circ} 02^{\prime} 49.0^{\prime \prime} \mathrm{S}, 39^{\circ} 25^{\prime} 56.0^{\prime \prime} \mathrm{W}, 400 \mathrm{~m}$ s.n.m., 24 fev. 2000 (fl.) J.G. Jardim 2869 (CEPEC, HUNEB, RB); Uruçuca, Serra do Conduru, $14 \mathrm{~km}$ a W de Serra Grande rodovia para Uruçuca, depois ao $\mathrm{S}$ do centro de operações do novo Parque Estadual Serra do Conduru, $14^{\circ} 29^{\prime} 00.0^{\prime}$ 'S, 3908'00.0”'W, 23 mar. 2000 (bot.), W.W. Thomas 12119 (CEPEC, HRCB, MBML, RB); Vitória da

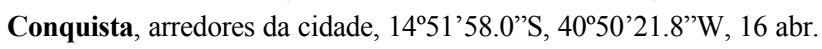
1995 (fl.), E. Melo 1210 (HRCB, HUEFS); Wenceslau Guimarães, Nova Esperança, Estação Ecológica Estadual Nova Esperança, trilha para o Pico do Urubu, parte inicial, $13^{\circ} 35^{\prime} 34.0^{\prime}$ 'S, 3942'58.0'W, 450 m s.n.m., 4 maio 2007 (fl.), J.G Jardim 5026 (CEPEC, NY, $\mathrm{RB})$.

Guapira opposita apresenta ampla variabilidade fenotípica das lâminas foliares (Santos et al. 2010), tanto no tamanho quanto na forma (Furlan 1995). É caracterizada pelas folhas elípticas a elípticolanceoladas (Reitz 1970) e pelas inflorescências com ramos predominantemente verticilados a subverticilados (Furlan 1996). Santos et al. (2010) revelaram que adaptações morfoanatômicas de suas folhas parecem favorecer a sobrevivência em diferentes ambientes. Isso porque o parênquima paliçádico em múltiplas camadas pode maximizar a taxa fotossintética e reduzir a susceptibilidade à fotoinibição quando as folhas são expostas ao sol.

\section{Guapira pernambucensis (Casar.) Lundell, Wrightia 4(2): 83. 1968.}

Figuras 8 e 9C, D.

Nome popular: farinha-seca-do-litoral (Silva 806), farinha-seca (Harley 18157), carne-de-vaca (Costa 178).

Arbustos até $3 \mathrm{~m}$ alt.; ramos sempre glabros, os adultos retos, estriados quando secos; gemas ca. $1 \mathrm{~mm}$ diâm., levemente estrigosas, ferrugíneas. Folhas sésseis a subsésseis; pecíolo 1-5 $\mathrm{mm}$ compr., glabro; lâmina 1,5-9,0 × 1,0-5,5 cm, cordiforme a oval, base cordada a arredondada, ápice cuneado a obtuso, margem inteira, nunca revoluta, subcoriácea a coriácea, glabra em ambas as faces, nervuras salientes na face abaxial. Inflorescências com ramos predominantemente verticilados a subverticilados, 3,5$9,0 \times 1,5-6,0 \mathrm{~cm}$, em cimeiras terminais, laxas, glabras a glabrescentes; pedúnculo atropurpúreo, 1,3-2,5 cm compr.; brácteas 8-16 $\mathrm{mm}$ compr., adpressas estrigosas, ferrugíneas na face abaxial. Flores glabras, as estaminadas 2-4 mm compr., as pistiladas ca. $2 \mathrm{~mm}$ compr. Antocarpos globosos a oblongos, 2-6 × 1-4 $\mathrm{mm}$, atropurpúreos a nigrescentes na maturidade, glabros, com coroa fechada ou ereta.

Guapira pernambucensis é endêmica do Brasil, ocorrendo no Espírito Santo, Rio de Janeiro e São Paulo e em todos os estados do Nordeste, porém sem 
registros no litoral do Piauí e Ceará (Sá 2016). A espécie ocorre sempre concentrada em uma faixa ao longo do litoral brasileiro (Furlan 1996). D10, E9, E10, F6, F8, G8, H8, I8, J8: Mata Atlântica. Coletada com flores praticamente o ano todo e com frutos principalmente entre dezembro e junho, mais esporadicamente em outubro.

Material selecionado - Alagoinhas, $12^{\circ} 11^{\prime} 06.0^{\prime \prime} \mathrm{S}$, 38²5'41.0"W, 24 abr. 2010 (bot.), E. Melo 8069 (HUEFS); Cairu, 13²9’12.8”S, 3902'38.0”W, 3 mar. 2010 (bot.), M.L.L. Martins 1612 (HURB); Canavieiras, 1539'23”S, 3856'13”'W, 7 jan. 2002 (fr., bot.), T.S. Nunes et al. 766 (HUNEB); Caravelas, 1740'04,8”'S, 39'10'27.1”W, 18 set. 2007 (fl.), H.M. Dias 273 (CEPEC, RB);

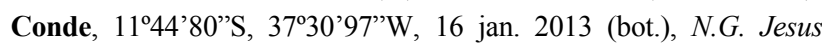
1659 (HUNEB); Entre Rios, 120'19'45”S, 37'52'84”W, 11 jan. 2001 (fr.), M.R. Fonseca \& M.C.R. Silva 28 (HUNEB); Esplanada, $12^{\circ} 06$ '25”S, 37041'53”W, 23 abr. 2004 (fr.), T. Ribeiro et al. 534 (HRB, RB); Guarajuba, loteamento Canto do Mar 12'38'03.1'S, 3803'34.1'W, 25 out. 1982 (fr.), H.P. Bautista 548 (HRB); Ilhéus, 1447'20.0”S, 3902'57.8”'W,15 jan. 1990 (fr.), A.M. Carvalho 2732 (HUEFS); Itanagra, 12¹9’37’S, 38 08’39’W, 19 jun. 1999 (fl.), F. França 3002 (UEFS, HRCB); Itapebi, 15¹3'17.6”'S, 3901'44.5”'W, 17 out. 1969 (bot.), J.A. Jesus 451 (RB); Ituberá, estrada para Pratigi,

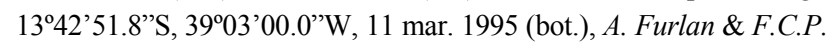

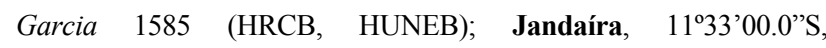
3707'00.0”'W, 31 jan. 2014 (fl.) M.L. Guedes 21283 (ALCB); Mata de São João, 12³1'49.1”S, 38¹7'57.1”W, 18 ago. 2010 (fl.), A.M. Miranda et al. 6210 (HUEFS); Maraú, $14^{\circ} 06 \mathrm{~S}, 39^{\circ} 01^{\prime} \mathrm{W}, 36 \mathrm{~m}$ s.n.m., 29 jan. 2008 (fl.), J.A. Lombardi et al. 7194 (HRCB, HUNEB); Nova Viçosa, Km 5 da rodovia Nova Viçosa-Posto da Mata, BR-101, 1753'30.8”'S, 39²2'18.8'W, 21 maio 1980 (fr.), L.A.M. Silva 806

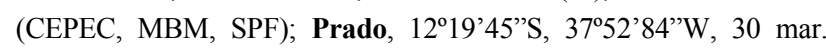
1989 (fr., bot.), L.A. Mattos-Silva et al. 2663 (CEPEC, HRCB, RB);

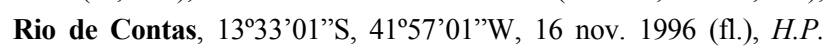
Bautista et al. 4369 (ALCB, CEPEC, HRB, HRCB); Salvador, 1256'40”'S, 38²7'07'W, 28 mar. 1998 (fl., fr.), J. Costa 178 (HRB, HUNEB); Santa Cruz Cabrália, 16¹6’51.4”S, 3901'30.0”W, 21 jan. 1977 (fl.), R.M. Harley18157 (K, SPF); Una, 15¹3'17,6”S, 3901'44,5”'W, 61 m s.n.m., 11 dez. 2011 (fl., fr.), J.A. Lombardi et al. 8871 (HRCB, HUNEB).

Guapira pernambucensis é facilmente reconhecida dentre as espécies de Guapira no Brasil por apresentar folhas glabras, sésseis, de base cordada. Nos botões estaminados e em suas folhas, é comum encontrar galhas de insetos (Maia \& Souza 2013). A espécie mais relacionada a ela é $G$. campestris, por ambas apresentarem folhas sésseis cordadas na base, embora G. pernambucensis apresente lamina cordiforme a oval (vs. elíptica a ovado-elíptica), com ápice cuneado a obtuso (vs. arredondado a retuso).

11.Guapira tomentosa (Casar.) Lundell, Wrightia 4(2): 84. 1968.

Figuras 7 e 9F, G.

Árvores ou arbustos, até $8 \mathrm{~m}$ alt.; ramos adultos retos, estriados quando secos, glabros, os jovens tomentosos, ferrugíneos a pardo; gemas ca. $3 \mathrm{~mm}$ diâm., hirsutas, castanhas. Folhas com pecíolo 4-6(-8) mm compr., velutino, castanho; lâmina 3-6(-12) × 1-
$2(-5) \mathrm{cm}$, elíptica a oblongo-elíptica, base aguda a atenuada, ápice agudo a curto-acuminado, margem revoluta, cartácea a subcoriácea, parda, incana na face adaxial, velutina na abaxial, nervura principal castanha, impressa na face abaxial. Inflorescências com ramos predominantemente verticilados a subverticilados, 1-2(7) $\times 0,5-1,5(-3) \mathrm{cm}$, dispostas em cimeiras terminais, congestas no ápice dos ramos, tomentosas, pardas; pedúnculo tomentoso, 1-2(-4) cm compr.; brácteas ca. 2 mm compr., hirsutas, castanhas na face abaxial. Flores castanhas, as estaminadas ca. $3 \mathrm{~mm}$ compr., incanas, as pistiladas ca. $2 \mathrm{~mm}$ compr., pilosas. Antocarpos oblongos a elipsoides, 4-6(-8) × 1-2(-4) mm, atropurpúreos a nigrescentes na maturidade, incanos, castanhos, geralmente com coroa fechada ou ereta.

Endêmica do Brasil, na Região Sudeste; conhecida apenas para o Espírito Santo, Minas Gerais e Rio de Janeiro (Furlan et al. 2008; Furlan \& Giulietti 2014; Sá 2016), é registrada pela primeira vez para a Bahia aqui. B5, B9, D8, D9, D10, E6, E8, E9, F6, I8: Mata Atlântica e ocasionalmente no Cerrado e Caatinga. Coletada com flores entre março e dezembro e com frutos entre dezembro e abril.

Material selecionado - Bonito, Chapada Diamantina, assentamento Piratini, próximo à represa, $12^{\circ} 04^{\prime} 29.0^{\prime \prime} \mathrm{S}$ 41²0'20.0”'W, 20 maio 2001(fl.) M.L. Guedes 8908 (ALCB); Candeias, região metropolitana de Salvador, próximo à cidade de Caboto, nas imediações do Porto de Aratu, 12\%45'39.0"S, 38 30'00.0”'W, 15 maio 2011 (fl.) M.L. Guedes 18300 (ALCB); Glória, Brejo do Burgo, Fazenda do Torrão, 09²0'17.0"S, 38¹5'16.9”'W, 28 nov. 1992 (fl.), F.P. Bandeira 92 (ALCB); Itacaré, Marambaia, 15 jul. 1995 (fl.), A.M. Carvalho 6040 (CEPEC, HRCB);

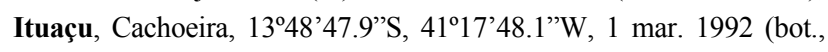
fl.), M.C. Ferreira 479 (HRB, HUEFS, HUNEB, RB); Jandaíra,

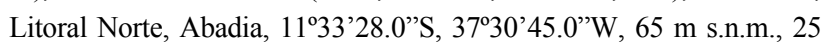
jan. 2011 (fr.), F.S. Gomes 630 (ALCB); Paulo Afonso, Serra do

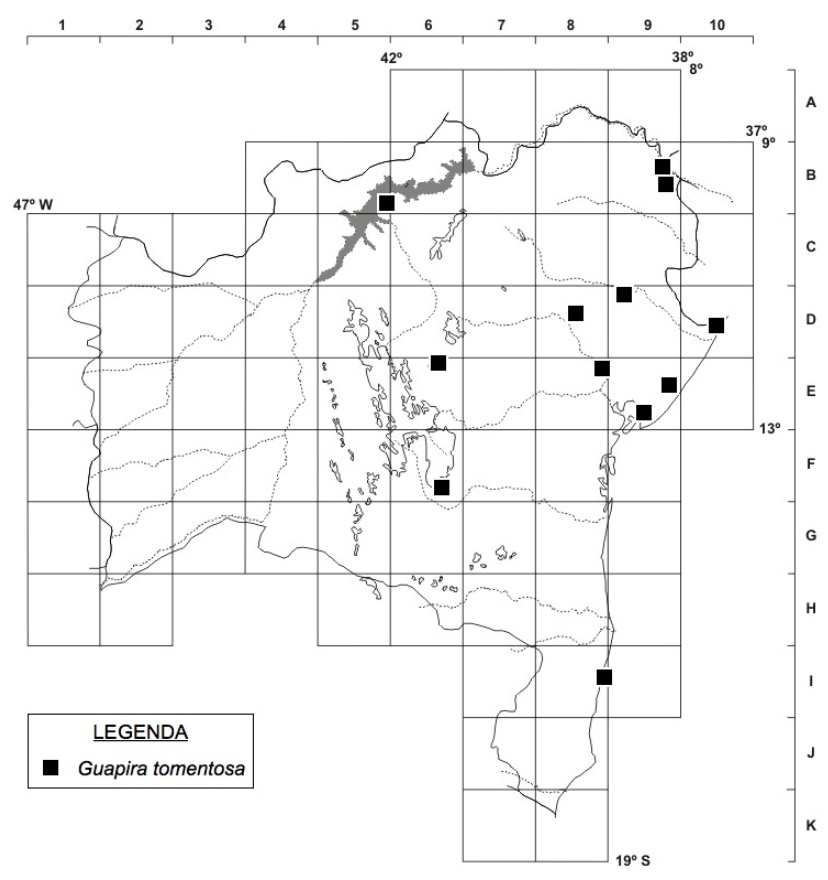

Figura 7. Distribuição de Guapira tomentosa no estado da Bahia. 
Umbuzeiro, 09³5'07’S, 38¹2'23”W, 3 ago. 2013 (est.), F.S. Souza 147 (HUNEB); Pojuca, fazenda Cosme e Damião, 12²2'05.7'S, 3809'51.3”W, 5 nov. 2009 (bot.), E.P. Queiroz 4013 (HRB); Porto Seguro, Extremo Sul, RPPN Mamona, 16²6'58.9”S, 3903'52.9”'W, 20 dez. 2005 (bot.), L.J. Alves 143 (ALCB); Sento Sé, subida do morro, 0951'32.0”'S, 4203'05.0”'W, 570 m s.n.m., 16 dez. 2007 (fr.), C. Correia 354 (HUEFS); Tucano, povoado Pedra Grande, na estrada

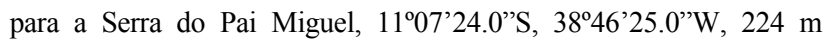
s.n.m., 20 dez. 2007 (fl.), D. Cardoso 2238 (HUEFS); Una, Reserva Biológica do Mico-Leão (IBAMA), entrada no $\mathrm{Km} 46$ da rodovia BR101 ilhéus-Una, 1209’05”S, $39^{\circ} 05^{\prime}$ W, 9 mar. 1993 (fl.), J.G. Jardim

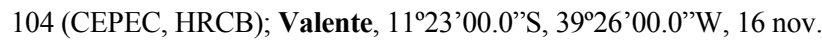
1986 (fl.), L.P. Queiroz 1116 (HUEFS).

Guapira tomentosa caracteriza-se pelas folhas tomentosas na face abaxial (Schmidt 1872), ramos tomentosos e ferrugíneos a pardos quando jovens, pecíolo sempre velutino. Está relacionada a $G$. hirsuta, da qual difere pelas inflorescências em cimeiras terminais, congestas no ápice dos ramos, e pela margem da lâmina foliar geralmente revoluta.

12. Guapira venosa (Choisy) Lundell, Wrightia 4(2): 84. 1968.

Figuras 8, 9H-J e 10C.

Nome popular: farinha-seca (Paixão 36).

Árvores ou arbustos, até $12 \mathrm{~m}$ alt.; ramos sempre glabros, os adultos retos, estriados quando secos; gemas ca. $4 \mathrm{~mm}$ diâm., levemente pilosas, ferrugíneas. Folhas com pecíolo 15-20(-30) mm compr., glabro; lâmina $10-19(-30) \times 5-8(-11) \mathrm{cm}$, elíptica a oblongoobovada, base aguda a obtusa, ápice agudo a obtuso, margem inteira, plana, cartácea a subcoriácea, glabra em ambas as faces, nervuras salientes na face abaxial. Inflorescências geralmente caulifloras, com ramos predominantemente opostos a subopostos (4-)7-12 $\times$ (3-) 5-11 cm, dispostas em cimeiras terminais ou

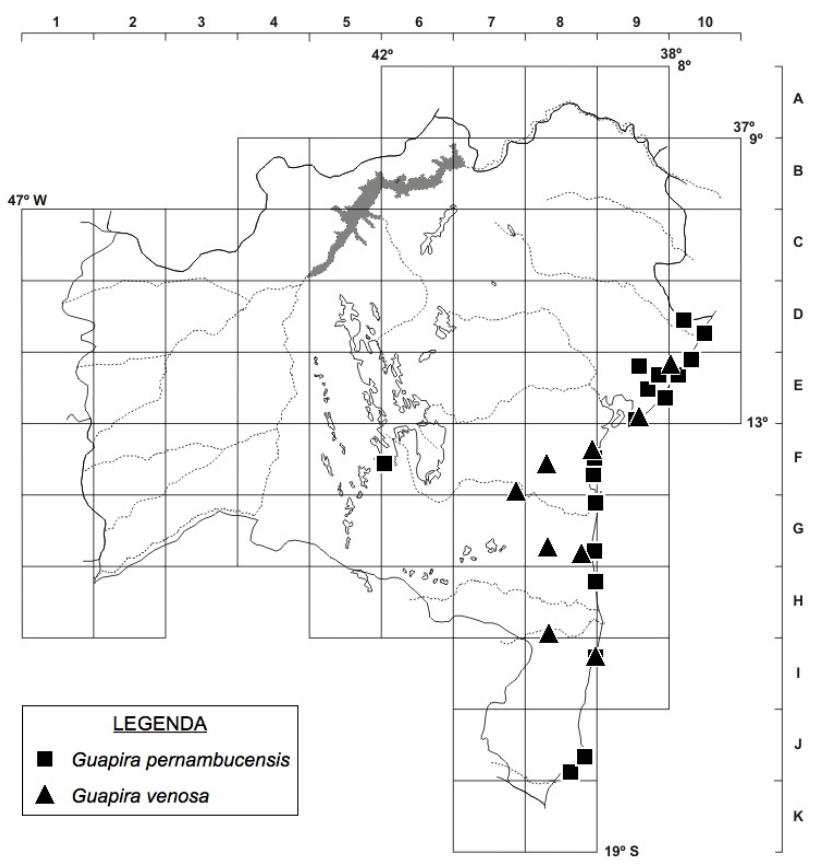

Figura 8. Distribuição de Guapira pernambucensis e G. venosa no estado da Bahia. axilares laxas, acastanhadas; pedúnculo glabro, ca. 7 cm compr.; brácteas 1-2 $\mathrm{mm}$ compr., pubescentes, ferrugíneas na face abaxial. Flores incanas, castanhas, as estaminadas 3-6 mm compr., as pistiladas $2-5 \mathrm{~mm}$ compr. Antocarpos globosos a oblongos, (5-)7-11 (4-)5-9 mm, atropurpúreos a nigrescentes na maturação, incanos, ferrugíneos, enrugados quando secos, geralmente com coroa fechada ou ereta.

Guapira venosa é endêmica do Brasil, ocorrendo em quase todos os estados da Região Norte (exceto em Roraima), além do Espírito Santo, Maranhão e Bahia (Sá 2016). E10, F7, F8, G8, H8, I8: Mata Atlântica. Floresce entre setembro e fevereiro e frutifica entre setembro e abril.

Material selecionado - Almadina, 5,3 km de Almadina, rodovia para Ibitupã, depois à esquerda, a 7,9 km da rodovia para Serra dos Sete Paus, 1444'11.0'S, 3941'57.0'W, 650 m s.n.m., 4 abr. 1997 (fr.), W.W. Thomas 11468 (NY, RB); Entre Rios, Algodão, $12^{\circ} 10^{\prime} 00.0^{\prime \prime} \mathrm{S}, 37^{\circ} 58^{\prime} 00.0^{\prime \prime} \mathrm{W}, 120$ m s.n.m., 20 fev. 2013 (fl.), A.V. Popovkin 1358 (HUEFS); Ilhéus, área do CEPEC, Km 22 da rodovia Ilhéus-Itabuna (BR-415), 14'50'00.0”'S, 39¹3'00.0’W, 9 dez. 1997 (fr.), J.L. Paixão 36 (CEPEC, HRCB, MBML, RB); Itapebi, cabeceira do rio São José, Pedra do Estevão, 1557'03.0”'S, 3940'35.0”'W, 478 m s.n.m., 21 nov. 2006 (fl.), A.P. Fontana et al. 2525 (MBML, RB); Jequié, fazenda Brejo Novo, a $13,6 \mathrm{~km}$ do bairro do Mandacaru, 135'06.0”S, 4007'37.0”'W, 690 m s.n.m., 6 fev. 2004 (fl.), W.W. Thomas 13862 (NY, RB); Salvador, Jardim Botânico de Salvador, 12 55'37'S, 38 25'37'W, 12 set. 2003 (fr.), E.P. Queiroz 333 (HRB); Santa Cruz Cabrália, Estação Ecológica do Pau-Brasil, ca. 17 km W de Porto Seguro, 16¹6’41.9”S, 3901'27.8”W, 18 out. 1978 (fl.), S.A. Mori et al. 10802 (NY, RB); Valença, estrada para Orobó, com entrada no Km 3 da rodovia Valença-BR-101, entre os Km 3 e 10, 1322'13.1'S, 3904'23.2”W, 7 fev. 1983 (fl.), A.M. Carvalho 1508 (HUESB, RB); Wenceslau Guimarães, Estação Ecológica Assentamento Patioba, 13'34'43”S, 3942'55'W, 450 m s.n.m., 11 mar. 2013 (fr.), L.Y.S. Aona et al. 2384 (FURB, HURB, RB).

Guapira venosa está proximamente relacionada a $G$. areolata pela inflorescência com ramos predominantemente opostos a subopostos, mas difere pelas folhas com nervuras muito salientes na face abaxial (Schmidt 1872). Furlan (1996) relata frequente caulifloria em $G$. venosa, condição também encontrada em exemplares da Bahia.

\section{Agradecimentos}

Os autores agradecem aos técnicos e curadores dos herbários ALCB, CEPEC, HRB, HRCB, HUEFS, HUNEB, HURB, RB e SPF, pela prestatividade e pelo acesso às coleções; à Universidade do Estado da BahiaUNEB, pelo apoio logístico e disponibilidade do espaço físico para desenvolvimento da pesquisa e construção deste artigo; ao Cyl F.C. Sá pelas significativas contribuições, à Nádia Roque pelas valorosas recomendações na banca de defesa da dissertação, à Daniela S. C. Torres pelas sugestões, à Carla T. de Lima pelas ilustrações e a A. Popovkin, M. Stefani, J. Medeiros e M. Mercadante pela concessão das fotografias. 


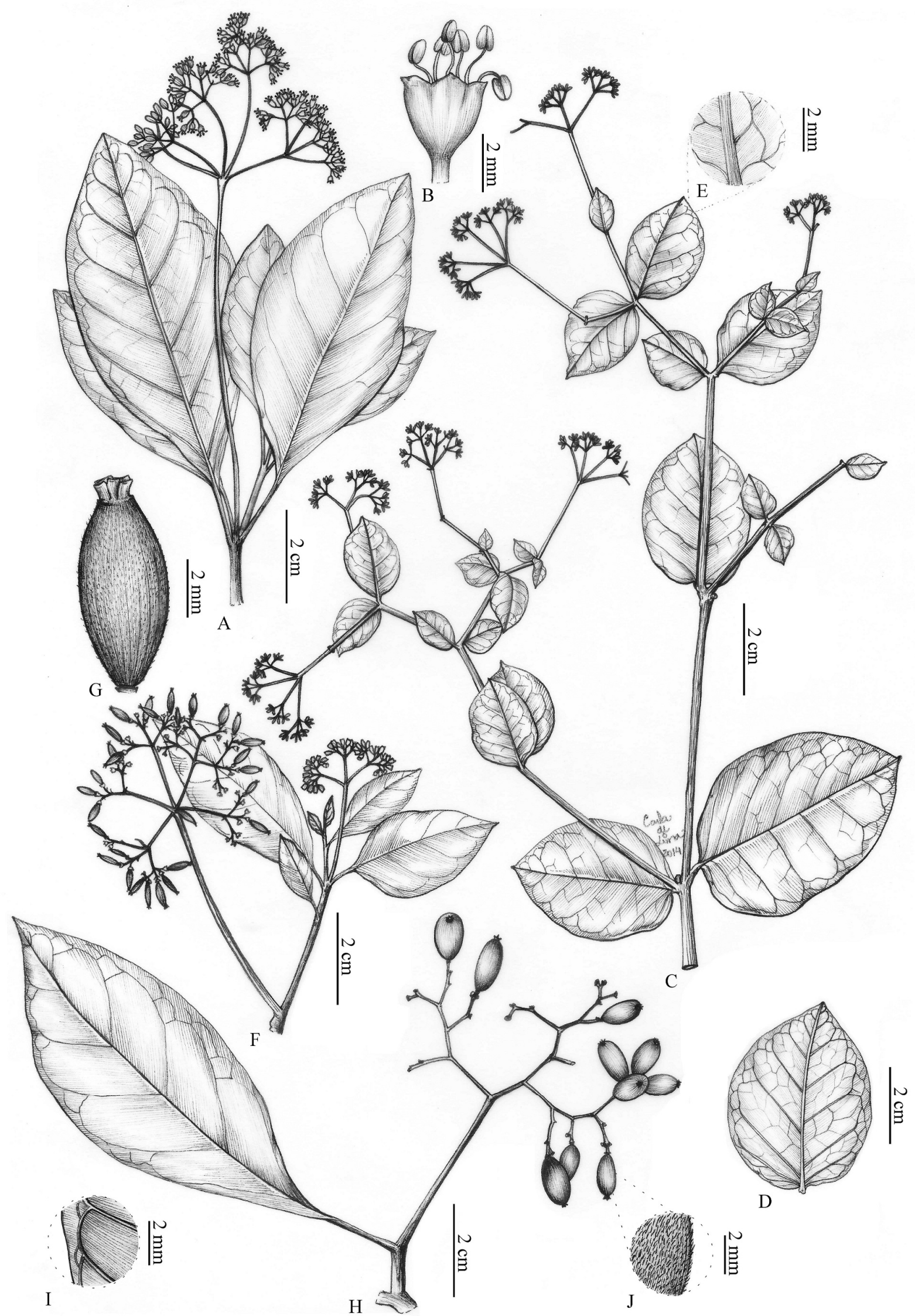

Figura 9. A, B. Guapira opposita: A- ramo florífero; B- flor estaminada, estames exsertos. C-E. G. pernambucensis: C- hábito; D- folha séssil a subséssil, face abaxial; E- detalhe da lâmina foliar evidenciando nervuras salientes, face abaxial. F, G. G. tomentosa: F- ramo com folhas e antocarpos; G- antocarpo incano, com coroa fechada, vista lateral. H-J. G. venosa: H- ramo com folha e antocarpos; I- detalhe da lâmina foliar evidenciando nervuras salientes, face abaxial; J- detalhe do antocarpo levemente incano (A, B- Aona 2510; C-E- Jesus 1659; F, G- Gomes 630; H-J- Queiroz 333). 

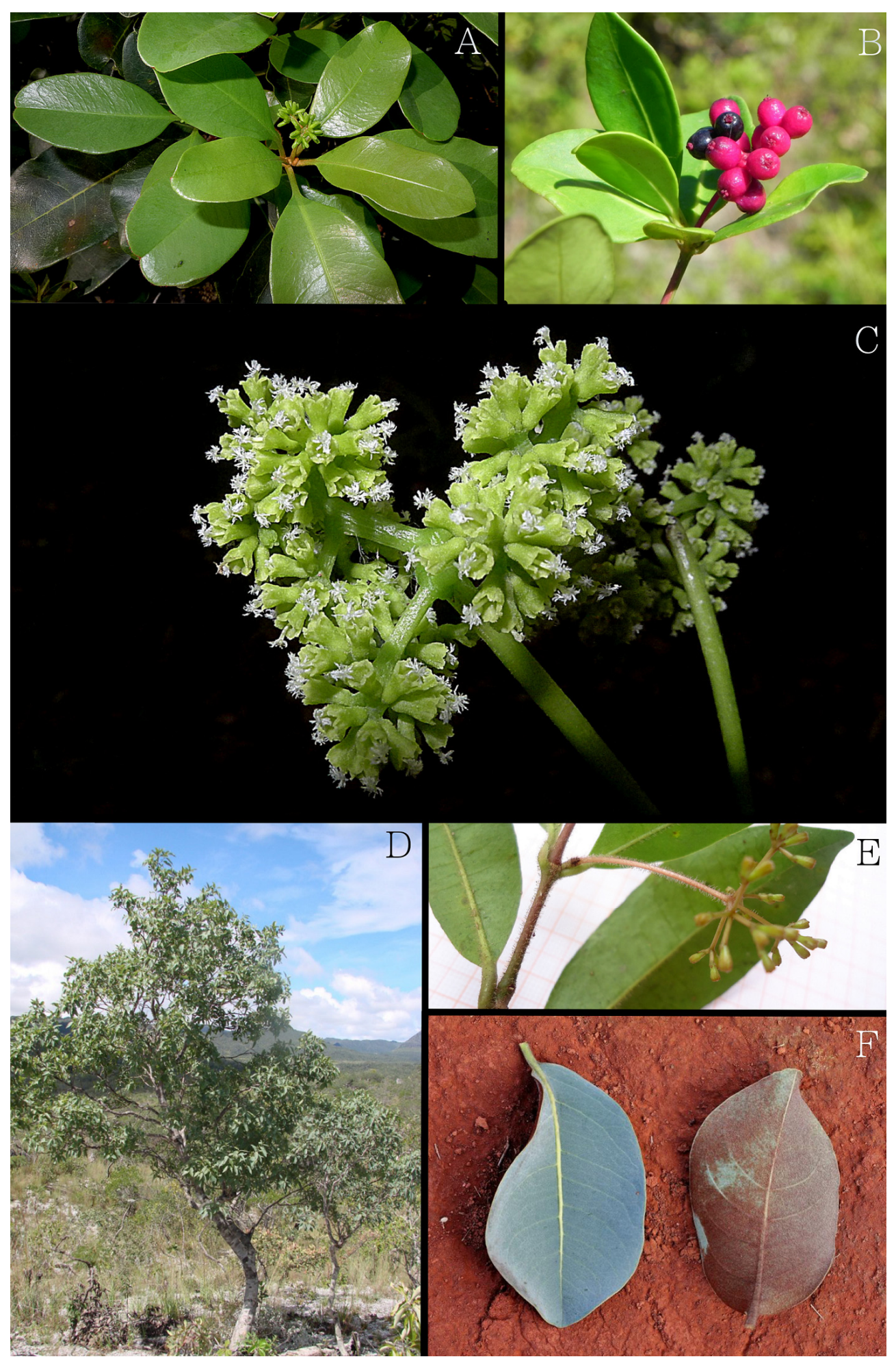

Figura 10. Representantes de Guapira da Bahia: A. G. obtusata: ramo com folhas e inflorescência com botões. B. G. opposita: ramo com folhas e antocarpos. C. G. venosa: inflorescência com flores pistiladas. D. G. graciliflora: hábito. E. G. hirsuta: ramo e inflorescência. F. G. noxia: folha (faces adaxial e abaxial). (Fotos: A, C, E- A. Popovkin; B- M. Stefani; D- J. Medeiros; F- M. Mercadante).

\section{REFERÊNCIAS}

Bittrich, V. \& Kühn, U. 1993. Nyctaginaceae. In: K. Kubitzki, J.G Rohwer \& V. Bittrich (eds), The Families and Genera of Flowering Plants. Vol. 2. Springer-Verlag, Berlin, p. 473-486.

Douglas, N.A. \& Manos, P.S. 2007. Molecular phylogeny of Nyctaginaceae: taxonomy, biogeography, and characters associated with a radiation of xerophytic genera in North America. American Journal of Botany 94: 856-872.

Douglas, N. \& Spellenberg, R. 2010. A new tribal classification of Nyctaginaceae. Taxon 59(3): 905-910.

Furlan, A. 1995. Nyctaginaceae. In: B.L. Stannard (ed.), Flora of the Pico das Almas, Chapada Diamantina, Bahia, Brasil. Royal Botanic Gardens, Kew, p. 517-519. 
Furlan, A. 1996. A Tribo Pisonieae Meisner (Nyctaginaceae) no Brasil. Tese (Doutorado em Ciências). Universidade de São Paulo, São Paulo.

Furlan, A. 2004. Flora de Grão-Mogol, Minas Gerais: Nyctaginaceae. Boletim de Botânica da Universidade de São Paulo 22: 339-341.

Furlan, A. \& Giulietti, A. M. 2014. A tribo Pisonieae Meisner (Nyctaginaceae) no Brasil. Boletim de Botânica da Universidade de São Paulo 32(2):145-268.

Furlan, A.; Udulutsch, R.G. \& Dias, P. 2008. Flora da Serra do Cipó, Minas Gerais: Nyctaginaceae. Boletim de Botânica da Universidade de São Paulo 26(1): 51-59.

Maia, V.C. \& Souza, M.D.C. 2013. Insect galls of the xeric vegetation of Ilha do Cabo Frio (Arraial do Cabo, RJ, Brazil). Biota Neotropica 13(3): 278-288.
Marchioretto, M.S.; Lippert, A.P.U. \& Silva, V.L. 2011. A família Nyctaginaceae Juss. no Rio Grande do Sul, Brasil. Pesquisas, Botânica 62: 129-162.

Reitz, R. 1970. Nictagináceas. In: R. Reitz (ed.), Flora Ilustrada Catarinense. Herbário Barbosa Rodrigues, Itajaí.

Sá, C.F.C. 2016. Nyctaginaceae. In: Lista de Espécies da Flora do Brasil. Jardim Botânico do Rio de Janeiro. Disponível em http://reflora.jbrj.gov.br/jabot/floradobrasil/FB10908; acesso em 1 ago. 2016.

Santos, M.; Junior, P.F.; Vailati, M.G. \& Paulilo, M.T.S. 2010. Aspectos estruturais de folhas de indivíduos de Guapira opposita (Vell.) Reitz (Nyctaginaceae) ocorrentes em Restinga e na Floresta Ombrófila Densa. Insula 39: 59-78.

Schmidt, J.A. 1872. Nyctagineae. In: C.F.P. Martius \& A.G. Eichler (eds), Flora Brasiliensis. Vol. 14, pars 2. München, Leipzig, p. 345-376.

\section{LISTA DE EXSICATAS}

Alves, L.J. 143 (11); Amorim, A.M. 1144 (4), 4266 (6), 7489 (9), 7708 (6); Aona, L.Y.S. 1954 (6), 2093 (8), 2103 (4), 2234 (9), 2294 (4), 2246 (3), 2384 (12), 2510 (9); Araújo, A.P.P. 105 (5); Bandeira, F.P. 92 (11); Bastos, N.G. 79 (8); Bautista, H.P. 548 (10), 4345 (3), 4369 (10); Borges, R.A.X. 782 (4); Brazão J.E.M. 141 (5); Cardoso, D. 1979 (4), 2238 (11); Carvalho, A.M. 1508 (12), 2732 (10), 5673 (3), 6040 (11), 6236 (3); Carvalho, G.M. s.n. CEPEC 140202 (1), s.n. CEPEC 140036 (3); Carvalho-Sobrinho, J.G. 61 (9); Conceição, A.S. 1101 (5); Correia, C. 354 (11); Costa, G. 816 (5); Costa, J. 178 (10); Daneu, L. 195 (9), 456 (6), 309 (9); Dias, H.M. $273(10) .284$ (9), 285 (6); Faria, L.S.S 954 (4); Farias, G.L. 177 (8); Ferreira, J.D.C.A. 408 (8); Ferreira, M.C. 478 (4), 479 (11), 693 (3), 888 (8); Fonseca, M.L. 8069 (2); Fonseca, M.R. 28 (10), 123 (7); Fontana, A.P. 2525 (12); França, F. 3155 (8), 3002 (10), 3380 (4); Furlan, A. 1585 (10); G.P.C., 720 (5), 861 (9); Gardner, G. 2944 (2); Gassom, P. 5972 (4), 6101 (8); Giordano, L.C.S. 2719 (8); Glaziou, A. 3083 (1); Gomes, F.S. 630 (11); Gonçalves, L.M.C. 217 (5); Guedes, M.L. 1527 (1), 8908 (11), 10852 (1), 12772 (3), 17859 (2), 18300 (11); 18433 (9), 19345 (5), 20102 (9), 20119 (1), 21283 (10); Harley, R.M. 18157 (10); H50244 (2), 55413 (4); Irwin, H.S. 32555 (8); Jardim, J.G. 104 (11), 2869 (9), 3823 (1), 5026 (9); Jesus, J.A. 451 (10); Jesus, N.G. 838 (9), 950 (8), 1619 (3), 1659 (10); Labouriau, M.S. 931 (5); Lombardi, J.A. 7194, 8871 (10); Maass, P.J.M. 7043 (2); Macedo, G.E.L. 550 (4); Macedo, G.E.L. 1817 (6); Martinelli, G. 9655 (8); Martins, M.L.L. 1612 (10); Matos, E.N. 2970 (6); Mattos-Silva, L.A. 2663 (10), 5187 (4); Melo, E. 1208 (3), 3728 (5), 4675 (4), 6629 (9), 8041 (1), 8069 (10), 11495 (5), 1210 (9), 12819 (4); Mendes, M.S. 450 (3); Mendonça, R.C. 1573 (3), Milliken, W. 5085 (8); Miranda, A.M. 6210 (10); Moraes, A.O. 73 (5); Mori, S.A. 10802 (12), 11103,12093 (5), 12704 (9), 12933 (3); Noblick, L.R. 2424,2934 (5); Nunes, T.S. 682 (5); 766 (10); Oliveira, F.C.A 860 (3); Paixão, J.L. 36 (12), 891 (9); Pirani, J.R. 1996 (4); Popovkin, A.V. 851 (2), 852 (3), 1358 (12), 1432 (4); Prates, A.R.S. 292 (9); Queiroz, E.P. 333 (12), 321 (3), 542 (7), 2195 (1), 4004 (8), 4013 (11); Queiroz, L.P. 1116 (11), 3249 (5), 5677 (2), 7021 (5), 9972 (4), 12772 (4); Ramos, C.H. 349 (9); Ribeiro, T. 534 (10), 4682 (7); Roque, N. 3314 (3); Santos, F.S. 528 (3); Silva, L.A.M. 806 (10); Silva, L.N. 53 (9); Silva, M.A. 3510 (2); Simões, S.S. 23 (4); Souza, F.S. 147 (11); Stradmann, M.T.S. 1065 (9); Thomas, W.W. 11361 (9), 11468 (12), $11885(3), 12119$ (9), 13463 (1), 13862 (12); Valadão, R.M. 324 (1); Venâncio, V.F. 108 (1); Walter, B.M.T. 2783 (7), 2943 (3); Zappi, D.C. 3380 (9). 